\title{
Invasibility and Recoverability of a Native Plant Community Following Invasion Depend on its Successional Stages
}

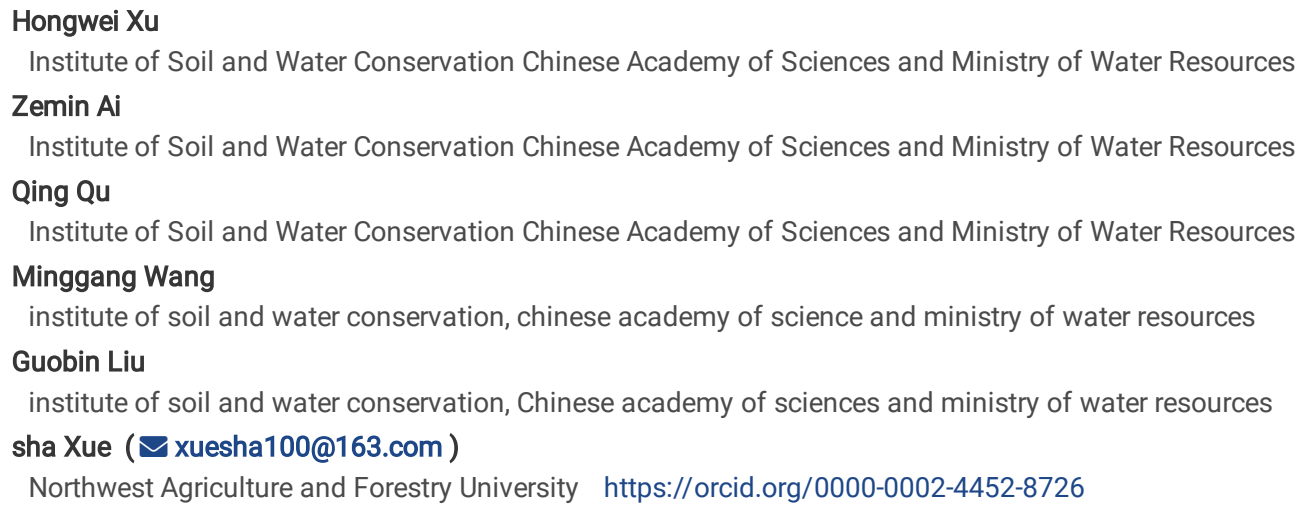

Research

Keywords: plant community, plant growth, exotic species removed, invasion advantage, recoverability, succession

Posted Date: December 17th, 2020

DOI: https://doi.org/10.21203/rs.3.rs-129092/v1

License: (c) (1) This work is licensed under a Creative Commons Attribution 4.0 International License. Read Full License

Version of Record: A version of this preprint was published at Soil Ecology Letters on June 14th, 2021. See the published version at https://doi.org/10.1007/s42832-021-0100-8. 


\section{Abstract}

Background: Exotic species invasions represent important causes of biodiversity loss in ecosystems. Yet, knowledge remains limited on the invasion advantage of exotic species (invasibility of native plants) and the ability of native species to recover following invasions at different stages of succession.

Results: We selected three grasses (Setaria viridis, Artemisia gmelinii, and Bothriochloa ischaemum) representing early, middle, and late successional species, respectively, and an exotic species (Panicum virgatum) from a stable grassland community. Four types of field soil were collected to treat the three early, middle, and later successional species, plus the exotic species. We examined the invasion ability of the exotic species on native communities and the recoverability of these communities following invasion across succession. We compared the performance of the four plant species grown in their "own" and "other" soils in a 2-year glasshouse experiment. Here we show that exotic species performed better in soils of early and mid-successional species, owing to higher soil nutrients and microbial residues, than in the soil of later successional species. In the soil of exotic species, early and mid-successional species exhibited poor growth, while that of later successional species was unchanged.

Conclusions: Our study demonstrated that soil nutrients and microbial residues create a soil legacy regulating the invasibility and recoverability (or resilience) of native plant communities and how it changed with vegetation succession.

\section{Introduction}

Global change is rapidly altering the composition and structure of biological communities; for instance, it provides opportunities for exotic species to invade and spread through natural ecosystems, representing an important cause for biodiversity loss [1, 2]. After exotic species invade new habitats, they spread under appropriate environmental conditions, interfering with and harming the structure, function, and ecological environment of invaded ecosystems [3]. Chemical or mechanical control is usually used to combat the negative effects of exotic species invasions on biodiversity and the environment [4], with the aim of restoring affected native plant communities [5]. Therefore, preventing exotic species invasion and restoring native species represent urgent management issues.

Exotic species invasions are highly complex; thus, it is important to evaluate the smoothness of exotic species invasions to elucidate the mechanisms involved and potential magnitude. The success of exotic species invasions is affected by regional climate and the soil environment [3]. Exotic species preferentially invade native plant species communities that have multiple nutrient utilization strategies and growth habits, as this allows them to quickly change the biotic and abiotic characteristics after invading [6, 7]. Yet, other studies show that exotic species invade native plant communities with similar nutrient utilization strategies and microbial adaptability to guarantee establishment and persistence [8]. Thus, systematic studies are required on the type of native plant communities that can be invaded by exotic species.

Secondary succession is the process of restoration and reconstruction of degraded ecosystems after the natural ecosystems are disturbed [9]. In this process, the compositions of the plant community and its environment produce an orderly developmental change in a certain direction [10]. In the succession sequence, species at different stages of succession have different life forms and nutrient utilization strategies [11]. Exotic species are generally more likely to invade young plant communities than mature plant communities [12]. Early to mid-succession species are considered young plant communities, with high nutrient requirements. Consequently, they have "expendable" nutrient utilization strategies and belong to unstable communities that are easily damaged by the environment, with low resistance and resilience stability [13]. Species at later stages of succession tend to be perennials with large rhizosphere ranges. They have a competitive advantage in nutrient absorption and "durable" nutrient utilization strategies [10], with strong resistance and recovery stability. However, while exotic species invasions are affected by the habitat conditions of plants [8], the stage of secondary succession (early, middle, later) most vulnerable to invasion remains unclarified.

Studying the recovery of native species after removing exotic species could improve our overall understanding of invasive species ecology and provide theoretical support for the restoration of native species in invaded areas. The removal of exotic species is an important challenge, because we must assess the effect to the plant community after removal and consider the potential risk of secondary invasions [2]. Exotic species often re-invade after being removed, because of residual effects on soil facilitating re-invasion [14]. Recovery has been examined by cutting invasive species in invaded plant community and comparing growth characteristics with plants in native areas [15]. Love \& Anderson [14] showed that the native plant community cannot recover after removing exotic species, whereas Guido \& Pillar [2] showed that different clipping methods (one-time cutting versus regular cutting) affect the growth of native plant species differently. Evaluation of plant-soil feedback showed that the soil of exotic species exhibits neutral feedback on the biomass of native species [16]. However, the stage of secondary succession (early, middle, later) most capable of recovering after exotic species are removed needs clarifying.

Thus, here, we evaluated the invasiveness of exotic species to native grassland communities, and the ability of these communities to recover, at different stages of secondary succession. For different stages of secondary succession, we explored (1) the invasiveness of exotic species on native plant communities (termed as invasibility) at different stages of secondary succession; (2) the ability of invaded native communities to recover from exotic species invasions (termed as recoverability), and the role of exotic species soil legacy on the recovery process; and (3) the extent to which exotic species invasibility and native species recoverability are influenced by the stage of succession. Therefore, we hypothesized that (1) exotic species could successfully invade native plant community soil but could obtain more biomass than when growing in their own native soil; (2) after the removal of exotic species, high soil legacy would allow native plant species to obtain more biomass than uninvaded soil; and (3) later succession species would have a stronger ability to resist exotic species invasion and stronger recoverability after exotic species removal than early and mid-succession species.

\section{Results}

\section{Plant biomass}


For the first growth period, the shoot and root biomass of Pv (exotic species) was significantly lower when planted in $E$, $M$, and $L$ soils than in Exo soils (Fig. 1a,b). The shoot and root biomass of Pv was significantly higher when planted in $E$ soils than in $M$ and $L$ soils (Fig. 1a,b). For the second growth period, the shoot and root biomass of Pv was significantly lower when planted in Exo-Sv and Exo-Bi soils than in Exo-Pv soils (Fig. 1c,d).

For the first growth period, the shoot and root biomass was significantly higher when Sv and Ag were planted in their own soils than in Exo soils. In comparison, the shoot and root biomass of Bi was significantly lower when planted in its own soils than in Exo soils (Fig. 2a,b). For the second growth period, the shoot and root biomass of Sv was significantly higher when planted in E-Sv soils than in E-Pv soils. The biomass of Ag was significantly higher when planted in M-Ag soils than in M-Pv soils. The biomass of Bi was significantly higher when planted in L-Bi soils than in L-Pv soils (Fig. 2c,d).

\section{Plant $\mathrm{C}, \mathrm{N}$, and $\mathrm{P}$ concentrations and stoichiometry}

Nitrogen and phosphorus (except E) concentrations of the shoot and root of Pv planted in the three native species soils were, overall, lower than those planted in Exo soils (Table 2). C:N and C:P ratios in the shoots of Pv were significantly higher when planted in $M$ and $L$ soils than in E and Exo soils. C:P and N:P ratios in the roots of $\mathrm{Pv}$ were significantly higher when planted in $\mathrm{M}$ than in all other soils (Table 2). For the second growth period, nitrogen and phosphorus concentrations in the shoots and roots of Pv were significantly higher when planted in Exo-Sv and Exo-Bi soils than in Exo-Pv soils. The C:P ratio in the shoots and the $\mathrm{C}: \mathrm{N}$ and $\mathrm{C}: \mathrm{P}$ ratios in the roots of Pv were significantly higher when planted in Exo-Bi soils than in Exo-Sv and Exo-Pv soils (Table 2).

Carbon, nitrogen, and phosphorus concentrations were significantly higher in the shoots of Sv and Ag planted in their own soils than in Exo soils. The C:N, C:P, and $\mathrm{N}$ :P ratios in the shoots and roots of $\mathrm{Sv}$ and in the shoots of Ag were significantly lower when planted in its own soils than in Exo soils (Table 3 ). The phosphorus concentration was higher in the shoots and roots of Bi planted in Exo soils than in $L$ soils. C:P and N:P ratios were significantly higher for Bi planted in L soils than in Exo soils (Table 3). For the second growth period, nitrogen and phosphorus concentrations were significantly higher in the shoots of Sv planted in E-Sv soils than in E-Pv soils. C:N ratios were significantly lower in the shoots of Sv planted in E-Sv soils than in E-Pv soils (Table 3). Carbon, nitrogen, and phosphorus concentrations were significantly higher in the shoots and roots of $\mathrm{Ag}$ and $\mathrm{Bi}$ planted in their own soils than in Pv soils. C:P and N:P ratios were lower in the shoots of $\mathrm{Ag}$ and $\mathrm{Bi}$, and $\mathrm{C}: \mathrm{N}$ and $\mathrm{C}: \mathrm{P}$ ratios were lower in the roots of $\mathrm{Ag}$, in their own soils than in Pv soils (Table 3 ).

\section{Soil chemical property}

SOC (except Exo-Sv), AP, and AN concentrations were significantly higher in Exo-Pv soils than in Exo-CK, Exo-Sv, and Exo-Bi soils (Table 4). After planting native and exotic species in native species soils, SOC, TN, TP, AP, and AN concentrations were higher in E-Sv soils than in E-CK and E-Pv soils. The concentrations of these parameters were higher in M-Ag soils than in M-CK and M-Pv soils. AP and AN concentrations were higher in L-Bi soils than in L-CK and L-Pv soils (Table 4).

\section{Soil biological property}

MBC, MBN, B-G, N-AG, and A-P were higher in Exo-Pv soils than in Exo-CK, Exo-Sv, and Exo-Bi soils. Bacterial diversity (Shannon index) and fungal richness (Chao1) were higher in Exo-Sv, Exo-Bi, and Exo-Pv than in Exo-CK. There was no significant difference in these two parameters in Exo-Sv, Exo-Bi, and Exo-Pv soils (Table 5). After planting native and exotic species in native soils, MBC, MBN, B-G, N-AG, and A-P were higher in E-Sv soils than in E-CK and E-Pv soils. These parameters were higher in M-Ag soils than in M-CK and M-Pv soils. These parameters were also higher in L-Bi soils than in L-CK and L-Pv soils (Table 5).

In all soils, the dominant bacterial phyla ware Proteobacteria, Acidobacteria, Actinobacteria, and Gemmatimonadetes (Fig. 3a,c,e,g). Acidobacteria dominated Exo-Pv and Exo-CK soils (Fig. 3a, Table S1). Acidobacteria dominated E-Sv soils (Fig. 3c, Table S1).

In all soils, the dominant fungal phyla were Ascomycota, Basidiomycota, and Glomeromycota (Fig. 3b,d,f,h). Basidiomycota dominated Exo-Pv soils (Fig. 3b, Table S1). No significant differences in bacteria and fungi were found at the phylum level in soils created by native plants and exotic plants (Pv) (Fig. 3d,e,f,g,h).

PCA and PERMANOVA showed that, compared to bare soil (-CK) (Fig. 4a-h, Table S2), all treatments showed variations in the bacterial and fungal community compositions (except for the bacterial community composition in L soils; Fig. 4d). No clear variation was detected in the composition of bacterial and fungal communities in the soils created by native species compared to the soils created by the exotic species (Pv) (Fig. 4a,b,d,e,g,h, Table S2), with the exception of ESv and E-Pv soils for bacterial community composition (Fig. 4c, Table S2) and M-Ag and M-Pv soils for fungal community composition (Fig. 4f, Table S2).

\section{Correlation networks of the soil microbial community}

Based on the relationship networks, bacteria captured 1210 edges, 1523 edges, 1455 edges, and 1434 edges, while fungi captured 61 edges, 98 edges, 70 edges, and 97 edges, for Exo-CK, Exo-Sv, Exo-Bi, and Exo-Pv, respectively (Fig. 5a, Table S3). Bacteria captured 1612 edges, 1484 edges, and 1413 edges, while fungi captured 119 edges, 115 edges, and 114 edges, for E-CK, E-Sv, and E-Pv, respectively (Fig. 5b, Table S3). Bacteria captured 1026 edges, 1090 edges, and 1195 edges, while fungi captured 101 edges, 94 edges, and 96 edges, for M-CK, M-Ag and M-Pv, respectively (Fig. 5c, Table S3). Bacteria captured 1027 edges, 1065 edges, and 1388 edges, while fungi captured 73 edges, 123 edges, and 169 edges, for L-CK, L-Bi, and L-Pv, respectively (Fig. 5d, Table S3).

\section{Discussion}

\section{Performance of exotic species}

Our results demonstrate that, compared to exotic species grown on their own soil, those grown on the three native species field soils (Experiment 1 ) and soils disturbed by native species (Experiment 2) did not gain higher biomass. This result confirmed our first hypothesis. These results are in contrast with those of 
existing studies suggesting that exotic species smoothly invade native plant communities and gain higher biomass $[17,18]$. This difference might be attributed to plant and soil interactions differing with species and site [13] or differences in the biological and abiotic characteristics of soils used in the current study [19]. Differences in biotic and abiotic soil conditions likely generate different plant-soil feedback effects, to a certain extent [20].

Exotic and native species are heterogeneous. Consequently, the original native soil environment has a competitive repulsive effect on exotic species, which hinders the invasion of exotic species [21]. The availability of soil resources is considered to be crucial for plant growth [18]. In our study, soil available nutrients (available nitrogen and phosphorus) were relatively lower in soils disturbed by native species than in soils disturbed by exotic species (Table 4). In addition, soil microorganisms might influence the growth of exotic plant species [6]. In our study, soil microbial biomass was generally higher in exotic species soils than in native species soils (Table 1). Furthermore, soil microbial biomass and enzyme activity were higher in soils disturbed by exotic species than in soils disturbed by native species (Table 5). Relatively high soil microbial activity provides the basic conditions for releasing available nutrients to the soil and breaking down difficult-to-decompose minerals, which help plants absorb and utilize them [9]. The invasion of exotic species breaks the soil balance by altering the microbial composition and diversity of soils [6, 22]. However, our study found no significant difference in the soil microbial diversity (changes to a and $\beta$ ) of exotic species soils disturbed by different plant species. Instead, we showed that soils disturbed by exotic species have higher quantities of certain bacteria (Acidobacteria) and fungi (Basidiomycota) at the phylum level. Acidobacteria use nitrite as a nitrogen source, respond to soil nutrient availability, and have a variety of active transporters [23]. Consequently, these bacteria influence the circulation of nutrient elements (especially nitrogen) in the soil. Basidiomycota are typically saprotrophic, and are very sensitive to the decomposition of organic matter [24]. In addition, the microbial correlation network provides a novel way of evaluating the interaction modes and processes of microbial communities [25]. In the bacteria correlation network, soil disturbance by exotic species had fewer edges; however, the ratio of positive correlation edges was higher than that of soils disturbed by native species (Table S3). These results demonstrate that strong coexistence exists in the interactions between bacterial groups, with low differentiation among bacterial groups. This phenomenon indicates that competition for resources is not fierce in soil disturbed by exotic species. In parallel, higher soil nutrient content stimulates the transformation of the relationship between species in microbial communities [26]. This special network of bacteria might accelerate the growth of plants to a certain level [27]. Thus, the biomass of exotic species was lower when planted in soil disturbed by native species than in soils disturbed by exotic species. Previous studies showed that the photosynthetic rate, growth rate, and resource competitiveness of plants are positively correlated with plant nitrogen and phosphorus concentrations, and negatively correlated with C:N and C:P ratios [28]. Our study demonstrated that exotic species do not have a strong invasive advantage because plants planted in native plant soils and soils disturbed by native species had lower plant nitrogen and phosphorus concentrations, and higher C:N and C:P (Table 3).

Our study also confirmed that soil origin is an important factor influencing the growth of exotic species. Our study showed that invasion advantage (intrusive) of exotic species is higher during the early stage of succession and lower during the later stage of succession, confirming our third hypothesis. Zhang \& van Kleunen [29] showed that the success of exotic species invasions is usually attributed to higher competitiveness. The soil of fast growing plant communities is more conducive to plant colonization [30]. Early successional species are pioneer species, which grow fast; consequently, the soil is easily colonized by exotic species. In comparison, later successional species are generally large and grow slowly. The soil during early succession has a positive feedback effect on the growth of other plants, which potentially enhances asymmetric competition for resources with other species [31]. In addition, relatively complex network relationships of bacteria and fungi were detected in soil disturbed by early species (edges and positive edges). Thus, the bacterial and fungal groups of soil disturbed by early species are mainly in symbiotic relationships. This complex microbial network promotes soil nutrient cycling and plant growth [27]. Nutrient levels were lower in soil disturbed by species during the later stage of succession (Table 4). Thus, there is less nutrients in the soil at this later stage that could be directly used by plants. This phenomenon was confirmed by the fact that exotic species planted in the soil of early successional species and soil created by early successional species had relatively higher nitrogen and phosphorus concentrations of plants, and lower C:P in shoots and roots (but not shoots)

(Table 2).

\section{Performance Of Native Species}

Early and mid-successional native species grown in their own soil did not obtain higher biomass than plants grown in the soil of exotic species (Experiment 1). This finding confirmed our second hypothesis. After the invasion of exotic species, balanced symbiotic relationships between the original plants and soil is destroyed [32], resulting in the formation of a soil environment that is conducive to the growth of the exotic species [17]. After exotic species are removed, the soil remains unconducive to recolonization by native species. Zubek et al. [33] showed that the metabolites produced by invasive species have novel effects on microorganisms in the soil. These secondary compounds directly hinder the roots of replanted plants from colonizing [34]. In parallel, native species have higher shoot nitrogen and phosphorus concentrations and lower C:N, C:P, and N:P when grown in their own soil than in exotic soil. The rapid growth of plants requires a large amount of ribosomal RNA to synthesize protein. Because ribosomal RNA contains a large amount of phosphorus, plants with lower $\mathrm{C}$ N and C:P have a higher growth rates [28].

The current study also demonstrated that later successional species obtained higher biomass in the soil of exotic species than in their own soil. Thus, we showed that the soil of exotic species has a highly species-specific effect on replanted plants. The recovery of plants depends on the stage of succession; in other words, the recovery of early and middle species is difficult following the removal of invasive species. In contrast, later species can be restored after exotic species are removed. Exotic species have clear underground effects [6]. For example, after long-term disturbance by exotic species, the soil has relatively high amounts of available nutrient pools, complemented with higher microbe activity in early to mid-successional species soils than in later successional species soil. Later successional species dominate in replacement succession and have a strong ability to compete for nutrition under the action of soil microorganisms in a new environment [10]. The later successional species in our study was a C4 plant, whereas the early and mid-successional species were C3 plants. C4 plants are generally assumed to have higher competitiveness and nutrient use efficiency than C3 plants [35]. In our study, late successional species had a higher phosphorus acquisition ability when grown in the soil of exotic species than in their own soil (Table 3). High phosphorus acquisition 
accelerates protein synthesis in plants. Therefore, in a new environment, later successional species are more able to enhance the absorption of nutrients and, hence, increase biomass, than early and mid-successional species.

Interestingly, the three native plants did not gain more biomass when grown in soil disturbed by exotic species than in their own soil (experiment 2). This result indicated that, although the three native species can recover after the removal of exotic species, recoverability is low. Differences in abiotic and biotic soil conditions strongly influence plant growth [36]. In our study, the residual effects of soil caused by different species were heterogeneous. Overall, soil disturbed by exotic species had lower soil nutrient residues, microbial biomass, and enzyme activity (Table 4, 5). This phenomenon might cause a high degree of heterogeneity in the growth of replanted plants [37]. The combination of low fertility and low enzyme activity creates a new environment in which species must adapt to survive. Thus, lower soil nutrient residues did not allow replanted plants to obtain high biomass. Plant-soil feedback confirmed that biological parameters have an effect within months [36]. Exotic species secrete various allelochemicals into the soil, which inhibit bacteria that are beneficial to plant growth [38]. They also secrete soil pathogens [32] that affect the growth of native plants. However, in the process of native species recovery after exotic species are removed, it is possible that (1) the accumulation of soil microorganisms actually impeded the growth of native species, or (2) beneficial microorganisms conducive to the growth of native species were inhibited. Thus, future studies must focus on elucidating these mechanisms. In this study, the diversity and composition of bacteria and fungi in the soil were not significantly impacted by native and exotic species soils. However, the complexity of the microbial correlation network differed among soils. Plant growth was mainly determined by the extent to which microorganisms were positively correlated. While microorganisms were still correlated in soil created by exotic species, the number of positive correlation edges for bacteria and fungi was lower than those in soil that created by native species (except for the fungus correlation network in soil created by later succession species). Thus, in soil disturbed by exotic species, microorganisms have a weak symbiotic relationship. There is a certain differentiation phenomenon and a certain competitive relationship in resource utilization. This complex relationship in the microbial community is closely related to soil nutrients [26]. Nutrient levels are lower in soils disturbed by exotic species, which affects the relationship of the microbial community, thus, restricting plant growth. In addition, species that grow in soils created by exotic species have lower carbon, nitrogen, and phosphorus concentrations, and higher C:N, C:P, and N:P ratios, particularly for plant shoots. This difference in plant nutrients reflects the dynamic balance between the soil nutrient supply and plant nutrient demand [28]. Plants better adapted to soils with lower soil nutrients might have lower plant nutrients, as demonstrated in our study, whereby nutrients in soils created by exotic species were lower overall (Table 4).

\section{Conclusions}

Overall, our results confirmed the hypothesis that exotic species can smoothly invade new areas but cannot obtain more biomass than when growing in their own soils. This phenomenon might be attributed to their own soils having higher soil nutrients and microbial residues. The invasibility of a native plant community is higher in the soils of species in later successional communities and lower in the soils of species in early and mid-successional communities. After exotic species were removed, field soils exhibited stronger recoverability for later successional species than for early and mid-successional species. However, after soil was disturbed by exotic species, the recoverability of all three native species was weak. Our study provided novel insights on soil and plant characteristics during plant invasion and restoration, strengthening our understanding of invasion and restoration ecology.

\section{Methods}

Setaria viridis (abbreviated as Sv), Artemisia gmelinii (Ag), and Bothriochloa ischaemum (Bi) were selected as representative plants of early, middle, and later successional species, respectively. Panicum virgatum $(\mathrm{Pv})$ was selected as the exotic species. These three native species are the dominant grass species of secondary succession on the Loess Plateau. Pv is a perennial C4 gramineous plant that is native to North America and Central America and has been grown as an energy plant since 1990, owing to its developed root system, high productivity, and strong ecological adaptability. In 1990, the Institute of Soil and Water Conservation, Chinese Academy of Sciences, and Ministry of Water Resources began introducing Pv in the Loess Plateau to restore the local ecological environment. This plant showed strong adaptability to extreme climatic conditions of high temperature and drought, with good soil and water conservation benefits [39].

\section{Seed and soil collection}

The seeds of the four species were obtained from adult plants at sampling sites (each plant species was collected from five sites) located at Ansai Research Station of the Chinese Academy of Sciences ( $36^{\circ} 51^{\prime} \mathrm{N}, 109^{\circ} 19^{\prime} \mathrm{E}, 1068-1309 \mathrm{~m}$ above sea level [a.s.I.]). The annual average precipitation and temperature of this area are $483 \mathrm{~mm}$ and $8.8{ }^{\circ} \mathrm{C}$, respectively. The soil type is loess soil. Soils were collected from the same location as the seeds (minimum of $20 \mathrm{~m} \times 20 \mathrm{~m}$ ), from April 25 to 30,2015 . Soil was collected from the 5-20 cm layer, after removing ground litter and soil in the $0-5 \mathrm{~cm}$ layer. The collected soil was passed through a $5 \mathrm{~mm}$ mesh and mixed evenly for pot planting. Average chemistry and microbial soil properties for the different field soil sources are presented in Table 1.

\section{Experimental set-up}

The experiment was carried out in the State Key Laboratory of Soil Erosion and Dryland Farming on the Loess Plateau, Institute of Soil and Water Conservation, Chinese Academy of Sciences and Ministry of Water Resources ( $34^{\circ} 12^{\prime} \mathrm{N}, 108^{\circ} 07^{\prime} \mathrm{E}, 530 \mathrm{~m}$ a.s.I.). Illumination time, light intensity, air temperature, and air humidity can be controlled in this facility. The average annual temperature and precipitation are $12.9^{\circ} \mathrm{C}$ and $637.6 \mathrm{~mm}$, respectively. Before the experiment, we measured the germination rate of the seeds, which exceeded $90 \%$. Pots were round containers (diameter $\times$ height: $15 \mathrm{~cm} \times 20 \mathrm{~cm}$ ). One kilogram of crushed stones (diameter about $1 \mathrm{~cm}$ ) was added to each pot to prevent soil hardening caused by watering. A plastic tube (diameter $\times$ height: $1 \mathrm{~cm} \times 25 \mathrm{~cm}$ ) was inserted as a watering channel in the pot, which terminated above the crushed stones. A piece of paper was added to separate the soil and crushed stones.

Experiment 1 
This experiment was conducted on May 4, 2016. Four types of field soil were collected to treat the three early, middle, and later successional species (referred to as $E, M$, and $L$ soils, respectively), plus the exotic species (Exo). To examine the performance of the exotic species Pv in all three soils, one Pv individual was grown in each of soil type (Fig. 6, red dotted line). To compare the performance of the three native species in their own soil and exotic soils, one Sv individual was grown in E soil, one Ag individual was grown in $\mathrm{M}$ soil, and one $\mathrm{Bi}$ individual was grown in $\mathrm{L}$ soil. These individual were compared with individual of the same species grown in Exo soils (Fig. 6, blue dotted line). There were 10 replicates for each plant species grown in each soil type. As the bare control, five pots with each soil type and no plants were prepared. One-hundred-and-twenty pots were used in this phase.

For the planting process, $2.8 \mathrm{~kg}$ soil samples were weighed and put in pots (based on dry weight). The total weight of each pot was recorded for later water control. Then, the plant seeds were evenly sown in the pots. After sowing, sufficient water was added. Two weeks later, the seedlings were thinned until four plants per pot remained for the field investigation. After thinning, regular watering and management were implemented. Water control was conducted twice a week (to be $80 \%$ of field capacity). The position of pots was changed weekly to limit any effect of microclimate on plant growth. After 4 months, four pots containing uniformly grown plants were selected to collect plant and soil samples for each treatment. The roots were removed from each pot. The soil was homogenized and returned to the same pot of the same treatment.

Experiment 2

This experiment was conducted on May 4, 2017. After harvesting the plant species in Experiment 1, the soils were collected and used to assess the recovery of native species following disturbance by exotic species and the invasion of exotic species following disturbance by native species. To determine the invasiveness of exotic species after disturbance by native species, Pv individual were grown in soils created from native species (Sv, Ag, and Bi) versus being grown in its own soils originating from Exo field soils (referred to as Exo-Sv, Exo-Ag, and Exo-Bi vs. Exo-Pv, respectively) (Fig. 6, black solid line). To determine the recovery of native species following disturbance by exotic species, Sv, Ag, and Bi individuals were grown in their own soils versus being grown in soils created from exotic species originating from the field soils of these native species (E-Sv vs. E-Pv; M-Ag vs. M-Pv; L-Bi vs. L-Pv, respectively) (Fig. 6, green solid line). There were five replicates for each plant species grown in each soil. Planting and management methods were the same as in Experiment 1 . Plants were grown for 4 months. Four pots of uniformly grown plants were selected from each treatment for plant and soil samples.

\section{Plant biomass harvest and soil sample collection}

The shoots were clipped along the soil surface after removing soil and dust from the plant. The entire root system was then dug out from the pot after removing surface debris. The roots were rinsed with distilled water. The shoot and root of each plants was weighed after drying to a constant weight at $70{ }^{\circ} \mathrm{C}$

After collecting the roots, the soil from each pot was mixed as our soil samples. Each soil sample was sieved through a $2 \mathrm{~mm}$ mesh to remove visible stones, litter, and debris. The soil sample was then divided into three parts for different analyses. The first part was stored in a $-80{ }^{\circ} \mathrm{C}$ refrigerator until analyses of soil microbial community structure and diversity. The second part was stored in a $4{ }^{\circ} \mathrm{C}$ refrigerator and was used to determine soil enzyme activity and soil microbial biomass. The third part was naturally separated and was used to analyze soil physicochemical properties.

\section{Chemical and biological analyses}

Soil organic carbon (SOC) and plant carbon concentrations were determined using $\mathrm{H}_{2} \mathrm{SO}_{4}-\mathrm{K}_{2} \mathrm{Cr}_{2} \mathrm{O}_{7}$ oxidation methods. Soil total nitrogen (TN) and plant nitrogen concentrations were determined by the Kjeldahl method. Soil total phosphorus (TP) and plant phosphorus concentrations were estimated by the molybdenum blue method. Available nitrogen (AN) was determined by the alkaline $\mathrm{KMnO}_{4}$ method. Available phosphorus (AP) was determined using the Olsen methods.

Soil microbial biomass was evaluated within 1 month of storing soil samples at $4{ }^{\circ} \mathrm{C}$. Soil microbial carbon (MBC) and microbial nitrogen (MBN) were measured by the chloroform fumigation-extraction method [40]. The soil enzymes activities of $\beta-1,4-g$ lucosidase (B-G), $\beta-1,4-N$-acetylglucosaminidase ( $N$-AG), and acid phosphatase (A-P) were determined using a method developed by Saiya-Cork et al.[41], which was described by Xu et al., [42], and Xue et al.[43].

Total bacterial DNA was extracted from samples using the Power Soil DNA Isolation Kit (MO BIO Laboratories) according to the manufacturer's protocol. DNA quality and quantity were assessed using ratios of $260 \mathrm{~nm} / 280 \mathrm{~nm}$ and $260 \mathrm{~nm} / 230 \mathrm{~nm}$. DNA was then stored at $-80^{\circ} \mathrm{C}$ until further processing. The V3-V4 region of the bacterial 16S rRNA gene was amplified with the common primer pair (forward primer, 5'-ACTCCTACGGGAGGCAGCA-3'; reverse primer, 5'GGACTACHVGGGTWTCTAAT-3') combined with adapter sequences and barcode sequences. PCR amplification was performed in a total volume of $50 \mu \mathrm{l}$, which contained $10 \mu$ l buffer, $0.2 \mu \mathrm{l}$ Q 5 High-Fidelity DNA Polymerase, $10 \mu \mathrm{l} \mathrm{High} \mathrm{GC} \mathrm{Enhancer,} 1 \mu \mathrm{l}$ dNTP, $10 \mu \mathrm{M}$ of each primer, and 60 ng genome DNA. Thermal cycling conditions were as follows: initial denaturation at $95^{\circ} \mathrm{C}$ for $5 \mathrm{~min}$, followed by 25 cycles at $95^{\circ} \mathrm{C}$ for $1 \mathrm{~min}, 50^{\circ} \mathrm{C}$ for $1 \mathrm{~min}$, and $72{ }^{\circ} \mathrm{C}$ for 1 min, with a final extension at $72^{\circ} \mathrm{C}$ for $7 \mathrm{~min}$. The PCR products from the first PCR step were purified through VAHTSTM DNA Clean Beads. A second round PCR was then performed in a $40 \mu \mathrm{l}$ reaction, which contained $20 \mu \mathrm{l} 2 \times$ Phusion HF MM, $8 \mu \mathrm{lddH} \mathrm{H}_{2} \mathrm{O}, 10 \mu \mathrm{M}$ of each primer, and $10 \mu \mathrm{PCR}$ products from the first step. Thermal cycling conditions were as follows: initial denaturation at $98^{\circ} \mathrm{C}$ for $30 \mathrm{~s}$, followed by 10 cycles at $98^{\circ} \mathrm{C}$ for $10 \mathrm{~s}, 65^{\circ} \mathrm{C}$ for $30 \mathrm{~s}$, and $72{ }^{\circ} \mathrm{C}$ for $30 \mathrm{~s}$, with a final extension at $72^{\circ} \mathrm{C}$ for $5 \mathrm{~min}$. Finally, all PCR products were quantified by Quant-iT ${ }^{\mathrm{Tm}}$ dsDNA HS Reagent and pooled together. High-throughput sequencing analysis of bacterial rRNA genes was performed on the purified, pooled sample using the Illumina HiSeq 2500 platform ( $2 \times 250$ paired ends) at Biomarker Technologies Corporation, Beijing, China.

\section{Data analysis}

To obtain optimized sequences, the original data were filtered using Trimmomatic (version 0.33), merged using FLASH (version 1.2.7), and chimeric reads were removed in UCHIME (version 4.2). The optimized sequences were then clustered to obtain operational taxonomic units (OTUs) with $97 \%$ similarity using UCLUST in QIIME (v1.8.0). Species were then classified according to the sequence composition of the OTUs. Taxonomy was assigned for each phylotype 
based on the SILVA database (release 132) for bacteria and the UNITE database (v7.0) for fungi. Based on the OTU analysis, taxonomic analysis was performed on samples at various taxonomic levels to obtain the phylum, class, order, family, genus, and species. Alpha diversity analysis was used to obtain the species diversity for soils of different origins. Chao1 and Shannon indexes of each sample were statistically calculated to $97 \%$ similarity. Principal component analysis (PCA) and permutational multivariate analysis of variance (PERMANOVA) were used to analyze the effects of soil origin on the composition of the bacterial and fungal community at the OTU level based on Bray-Curtis distance.

Correlation networks were selected to study the correlation of the soil microbial community at the genus level. First, the correlation matrix of the genus for which the relative abundance exceeded $0.1 \%$ was calculated using the Spearman correlation analysis (psych package in R. v.4.0.2). Then, Gephi 0.9.2 software was used to visualize the bacterial and fungal network and obtain the network structure. One node represented one genus type. The size of the node indicated the relative abundance of the genus. The color of the line between nodes indicates the positive and negative correlation of different genera.

One-way ANOVA and t-tests were used to test the effects of soil origin on plant and soil characteristics. The data were first tested for normality with Kolmogorov-Smirnov procedures (Lilliefors) and homogeneity with Levene's test. One-way ANOVA [Duncan's post-hoc tests (normal), Tamhane (non-normal)] and t-tests were performed on data that obeyed the normal distribution. For data that did not conform to the normal distribution, $L O G(X+1) \operatorname{conversion}$ was performed. If it still did not obey the normal distribution, the Kruskal-Wallis Test $(\mathrm{H})$ was used to perform a non-parametric test.

\section{Declarations}

\section{Ethics approval and consent to participate}

Not applicable.

\section{Consent for publication}

Not applicable.

\section{Availability of data and material}

The dataset supporting the conclusions of this manuscript will be uploaded to the database as soon as possible.

\section{Competing interests}

The authors declare that they have no conflict of interest.

\section{Funding}

This research were funded by the Natural Science Foundation of China (41907409 and 41771557), and Special Scientific Research Project of Education Department of Shaanxi Provincial Government (19JK0524).

\section{Authors' contributions}

H.X., Z.A., and S.X. designed the experiment; H.X., G.B., M.G., and Q.Q. analyzed the data; H.X. and Z.A. wrote the manuscript. All authors made important contributions to the manuscript, and approved publication.

\section{Acknowledgements}

We thank the editor and the reviewers for providing valuable comments and suggestions on our manuscript. We would like to thank Editage (www.editage.cn) for English language editing.

\section{References}

1. Germain RM, Srivastava D, Angert AL. Evolution of an inferior competitor increases resistance to biological invasion. Net Ecol Evol. 2020;4:419-25.

2. Guido A, Pillar VD. Invasive plant removal: assessing community impact and recovery from invasion. J Appl Ecol. 2017;54:1230-7.

3. Divisek J, Chytry M, Beckage B, Gotelli NJ, Lososova Z, Pysek P, Richardson DM, Molofsky J. Similarity of introduced plant species to native ones facilitates naturalization, but differences enhance invasion success. Nat Commun. 2018;9:4631.

4. Kettenring KM, Adams CR. Lessons learned from invasive plant control experiments: a systematic review and meta-analysis. J Appl Ecol. 2011;48:970-9.

5. Flory SL, Clay K. Invasive plant removal method determines native plant community responses. J Appl Ecol. 2009;46:434-42.

6. Zhang HY, Goncalves P, Copeland E, Qi SS, Dai ZC, Li GL, Wang C, Du D, Thomas T. Invasion by the weed Conyza canadensis alters soil nutrient supply and shifts microbiota structure. Soil Biol Biochem. 2020;143:107739.

7. Jiang Y, Luan L, Hu K, Liu M, Chen Z, Geisen S, Chen X, Li H, Xu Q, Bonkowski M, Sun B. Trophic interactions as determinants of the arbuscular mycorrhizal fungal community with cascading plant-promoting consequences. Microbiome. 2020;8:142.

8. Lososova Z, de Bello F, Chytry M, Kuehn I, Pysek P, Sadlo J, Winter M, Zeleny D. Alien plants invade more phylogenetically clustered community types and cause even stronger clustering. Glob Ecol Biogeogr. 2015;24:786-94. 
9. Krishna M, Gupta S, Delgado-Baquerizo M, Morrien E, Garkoti SC, Chaturvedi R, Ahmad S. Successional trajectory of bacterial communities in soil are shaped by plant-driven changes during secondary succession (vol 10, 9864, 2020). Sci Rep. 2020;10:9864.

10. Li SP, Cadotte MW, Meiners SJ, Hua ZS, Jiang L, Shu WS. Species colonisation, not competitive exclusion, drives community overdispersion over longterm succession. Ecol Lett. 2015;18:964-73.

11. Kardol P, Bezemer TM, van der Putten WH. Temporal variation in plant-soil feedback controls succession. Ecol Lett. 2006;9:1080-8.

12. Flory SL, Clay K. Effects of roads and forest successional age on experimental plant invasions. Biol Conserv. 2009;142:2531-7.

13. van de Voorde TFJ, van der Putten WH, Bezemer TM. Intra- and interspecific plant-soil interactions, soil legacies and priority effects during old-field succession. J Ecol. 2011;99:945-53.

14. Love JP, Anderson JT. Seasonal Effects of Four Control Methods on the Invasive Morrow's Honeysuckle (Lonicera morrowii) and Initial Responses of Understory Plants in a Southwestern Pennsylvania Old Field. Restor Ecol. 2009;17:549-59.

15. Guido A, Pillar VD, Palmer M. Are removal experiments effective tools for assessing plant community resistance and recovery from invasion? J Veg Sci. 2015;26:608-13.

16. Shannon SM, Bauer JT, Anderson WE, Reynolds HL. Plant-soil feedbacks between invasive shrubs and native forest understory species lead to shifts in the abundance of mycorrhizal fungi. Plant Soil. 2014;382:317-28.

17. Pearse IS, Sofaer HR, Zaya DN, Spyreas G. Non-native plants have greater impacts because of differing per-capita effects and nonlinear abundanceimpact curves. Ecol Lett. 2019;22:1214-20.

18. Valliere JM, Escobedo EB, Bucciarelli GM, Sharifı MR, Rundel PW. Invasive annuals respond more negatively to drought than native species. New Phytol. 2019;223:1647-56.

19. Kos M, Tuijl MAB, de Roo J, Mulder PPJ, Bezemer TM. Species-specific plant-soil feedback effects on above-ground plant-insect interactions. J Ecol. 2015;103:904-14.

20. Bezemer B, Lawson TM, Hedlund CS, Edwards K, Brook AR, Igual AJ, Mortimer JM, Van der Putten SR. WH. Plant species and functional group effects on abiotic and microbial soil properties and plant-soil feedback responses in two grasslands. J Ecol. 2006;94:893-904.

21. Cavender-Bares J, Kozak KH, Fine PVA, Kembel SW. The merging of community ecology and phylogenetic biology. Ecol Lett. 2009;12:693-715.

22. Li YP, Feng YL, Chen YJ, Tian YH. Soil microbes alleviate allelopathy of invasive plants. Sci Bull. 2015;60:1083-91.

23. Kielak AM, Barreto CC, Kowalchuk GA, van Veen JA, Kuramae EE. The Ecology of Acidobacteria: Moving beyond Genes and Genomes. Front Microbiol. $2016 ; 7: 744$.

24. Curlevski NJA, Xu Z, Anderson IC, Cairney JWG. Converting Australian tropical rainforest to native Araucariaceae plantations alters soil fungal communities. Soil Biol Biochem. 2010;42:14-20.

25. Mamet SD, Redlick E, Brabant M, Lamb EG, Helgason BL, Stanley K, Siciliano SD. Structural equation modeling of a winnowed soil microbiome identifies how invasive plants re-structure microbial networks. ISME J. 2019;13:1988-96.

26. Loranger-Merciris G, Barthes L, Gastine A, Leadley P. Rapid effects of plant species diversity and identity on soil microbial communities in experimental grassland ecosystems. Soil Biol Biochem. 2006;38:2336-43.

27. Tian J, He N, Kong W, Deng Y, Feng K, Green SM, Wang XB, Zhou JZ, Kuzyakov Y, Ye GR. Deforestation decreases spatial turnover and alters the network interactions in soil bacterial communities. Soil Biol Biochem. 2018;123:80-6.

28. Yang X, Huang Z, Zhang K, Cornelissen JHC. C:N:P stoichiometry of Artemisia species and close relatives across northern China: unravelling effects of climate, soil and taxonomy. J Ecol. 2015;103:1020-31.

29. Zhang Z, van Kleunen M. Common alien plants are more competitive than rare natives but not than common natives. Ecol Lett. 2019;22:1378-86.

30. Baxendale C, Orwin KH, Poly F, Pommier T, Bardgett RD. Are plant-soil feedback responses explained by plant traits? New Phytol. 2014;204:408-23.

31. Weiner J. Asymmetric competition in plant populations. Trends Ecol Evol. 1990;5:360-4.

32. Mangla S, Inderjit, Callaway RM. Exotic invasive plant accumulates native soil pathogens which inhibit native plants. J Ecol. 2008;96:58-67.

33. Zubek S, Majewska ML, Baszkowski J, Stefanowicz AM, Nobis M, Kapusta P. Invasive plants affect arbuscular mycorrhizal fungi abundance and species richness as well as the performance of native plants grown in invaded soils. Biol Fertil Soils. 2016;52:879-93.

34. Callaway RM, Cipollini D, Barto K, Thelen GC, Hallett SG, Prati D, Stinson K, Klironomos J. Novel weapons: Invasive plant suppresses fungal mutualists in America but not in its native Europe. Ecology. 2008;89:1043-55.

35. Pearcy RW, Ehleringer J. Comparative ecophysiology of C3 and C4 plants. Plant Cell Environ. 1984;7:1-13.

36. Bever JD, Westover KM, Antonovics J. Incorporating the soil community into plant population dynamics: the utility of the feedback approach. J Ecol. 1997;85:561-73.

37. Chen E, Liao H, Chen B, Peng S. Arbuscular mycorrhizal fungi are a double-edged sword in plant invasion controlled by phosphorus concentration. New Phytol. 2020;226:295-300.

38. Favaretto A, Scheffer-Basso SM, Felini V, Zoch AN, Carneiro CM. Growth of white clover seedlings treated with aqueous extracts of leaf and root of tough lovegrass. Rev Bras Zootecn. 2011;40:1168-72.

39. Ma Y, An Y, Shui J, Sun Z. Adaptability evaluation of switchgrass (Panicum virgatum L.) cultivars on the Loess Plateau of China. Plant Sci. 2011;181:638-43.

40. Vance ED, Brookes PC, Jenkinson DS. An extraction method for measuring soil microbial biomass C. Soil Biol Biochem. 1987;19:703-7. 
41. Saiya-Cork KR, Sinsabaugh RL, Zak DR. The effects of long term nitrogen deposition on extracellular enzyme activity in an Acer saccharum forest soil. Soil Biol Biochem. 2002;34:1309-15.

42. Xu H, Qu Q, Chen Y, Liu G, Xue S. Responses of soil enzyme activity and soil organic carbon stability over time after cropland abandonment in different vegetation zones of the Loess Plateau of China. Catena. 2021;196:104812.

43. Xue S, Yang X, Liu G, Gai L, Zhang C, Ritsema CJ, Geissen V. Effects of elevated CO 2 and drought on the microbial biomass and enzymatic activities in the rhizospheres of two grass species in Chinese loess soil. Geoderma. 2017;286:25-34.

\section{Tables}

Table 1 Average chemistry and microbial soil properties of field soils.

\begin{tabular}{|llllllll|}
\hline Soil origin & $\mathrm{SOC}\left(\mathrm{g} \mathrm{kg}^{-1}\right)$ & $\mathrm{TN}\left(\mathrm{g} \mathrm{kg}^{-1}\right)$ & $\mathrm{TP}\left(\mathrm{g} \mathrm{kg}^{-1}\right)$ & $\mathrm{AP}\left(\mathrm{mg} \mathrm{kg}^{-1}\right)$ & $\mathrm{AN}\left(\mathrm{mg} \mathrm{kg}^{-1}\right)$ & $\mathrm{MBC}\left(\mathrm{mg} \mathrm{kg}^{-1}\right)$ & $\left.\mathrm{MBN}(\mathrm{mg} \mathrm{kg})^{-1}\right)$ \\
\hline $\mathrm{E}$ & 5.53 & 0.62 & 0.54 & 1.65 & 46.36 & 211.04 & 9.96 \\
\hline $\mathrm{M}$ & 5.28 & 0.54 & 0.52 & 1.53 & 51.41 & 98.33 & 8.46 \\
\hline $\mathrm{L}$ & 5.29 & 0.51 & 0.49 & 0.91 & 44.58 & 201.49 & 9.94 \\
\hline Exo & 4.79 & 0.51 & 0.55 & 1.65 & 60.94 & 221.25 & 13.11 \\
\hline
\end{tabular}

Notes: E, early replacement succession field soil. M, middle replacement succession field soil. L, later replacement succession field soil. Exo, exotic species field soil. SOC, soil organic carbon. TN, soil total nitrogen. TP, soil total phosphorus. AP, soil available phosphorus. AN, soil available nitrogen. MBC, soil microbial biomass carbon. MBN, soil microbial biomass nitrogen.

Table 2 Mean ( \pm SE) of plant carbon, nitrogen, and phosphorus concentrations and stoichiometry of Panicum virgatum (Pv) planted in soils of different origin.

\begin{tabular}{|c|c|c|c|c|c|c|c|c|c|c|c|c|}
\hline \multirow[t]{3}{*}{ Soil origin } & \multicolumn{6}{|l|}{ Shoot } & \multicolumn{6}{|l|}{ Root } \\
\hline & Carbon & Nitrogen & Phosphorus & $\mathrm{C}: \mathrm{N}$ & $\mathrm{C}: \mathrm{P}$ & $\mathrm{N}: \mathrm{P}$ & Carbon & Nitrogen & Phosphorus & C:N & $\mathrm{C}: \mathrm{P}$ & $N: P$ \\
\hline & $\nabla \mathrm{g} / \mathrm{kg} \rrbracket$ & $\nabla \mathrm{g} / \mathrm{kg} \rrbracket$ & $\nabla \mathrm{g} / \mathrm{kg} \rrbracket$ & & & & $\nabla \mathrm{g} / \mathrm{kg} \rrbracket$ & $\nabla \mathrm{g} / \mathrm{kg} \rrbracket$ & $\llbracket \mathrm{g} / \mathrm{kg} \rrbracket$ & & & \\
\hline \multirow[t]{2}{*}{$E$} & $530.24 \pm$ & $8.88 \pm$ & $0.69 \pm$ & $60.19 \pm$ & $765.09 \pm$ & $12.81 \pm$ & $384.93 \pm$ & $7.43 \pm$ & $0.60 \pm$ & $51.99 \pm$ & $641.56 \pm$ & $12.40 \pm$ \\
\hline & 3.17 & $0.43 a b$ & $0.01 a$ & 3.08ab & $11.08 b$ & 0.67 & $1.06 a b$ & $0.24 a b$ & $0.02 a$ & 1.83 & $15.40 \mathrm{~b}$ & $0.62 c$ \\
\hline \multirow[t]{2}{*}{ M } & $539.63 \pm$ & $7.97 \pm$ & $0.62 \pm$ & $67.87 \pm$ & $868.51 \pm$ & $12.88 \pm$ & $370.90 \pm$ & $7.35 \pm$ & $0.44 \pm$ & $50.60 \pm$ & $849.50 \pm$ & $16.78 \pm$ \\
\hline & 21.32 & $0.22 \mathrm{bc}$ & $0.02 b$ & $3.33 a$ & $14.09 a$ & 0.59 & $2.27 \mathrm{bc}$ & $0.22 a b$ & $0.02 c$ & 1.35 & $40.72 a$ & $0.58 a$ \\
\hline \multirow[t]{2}{*}{ L } & $526.53 \pm$ & $7.76 \pm$ & $0.61 \pm$ & $67.99 \pm$ & $868.17 \pm$ & $12.82 \pm$ & $362.51 \pm$ & $7.19 \pm$ & $0.50 \pm$ & $50.47 \pm$ & $724.46 \pm$ & $14.34 \pm$ \\
\hline & 4.97 & $0.22 c$ & $0.03 b$ & $1.57 a$ & $46.80 a$ & 0.93 & $8.09 c$ & $0.12 b$ & $0.01 b$ & 1.17 & $32.22 b$ & $0.43 b$ \\
\hline \multirow[t]{2}{*}{ Exo } & $532.58 \pm$ & $9.75 \pm$ & $0.72 \pm$ & $54.75 \pm$ & $738.27 \pm$ & $13.53 \pm$ & $393.28 \pm$ & $8.08 \pm$ & $0.62 \pm$ & $48.85 \pm$ & $640.51 \pm$ & $13.16 \pm$ \\
\hline & 10.27 & $0.35 a$ & $0.00 \mathrm{a}$ & $1.69 b$ & $11.98 b$ & 0.50 & $8.29 a$ & $0.31 a$ & $0.01 a$ & 1.81 & $25.32 b$ & $0.66 \mathrm{bc}$ \\
\hline \multirow[t]{2}{*}{ Exo-Sv } & $413.43 \pm$ & $9.22 \pm$ & $1.57 \pm$ & $45.05 \pm$ & $265.99 \pm$ & $5.90 \pm$ & $303.80 \pm$ & $5.20 \pm$ & $0.90 \pm$ & $59.44 \pm$ & $336.77 \pm$ & $5.79 \pm$ \\
\hline & 3.48 & 0.41 & 0.09 & 1.73 & 14.70 & $0.14 a b$ & $1.62 \mathrm{a}$ & $0.39 a b$ & $0.02 b$ & 4.37ab & $9.12 \mathrm{~b}$ & 0.55 \\
\hline \multirow[t]{2}{*}{ Exo-Bi } & $404.77 \pm$ & $9.07 \pm$ & $1.49 \pm$ & $44.75 \pm$ & $273.08 \pm$ & $6.10 \pm$ & $289.44 \pm$ & $4.51 \pm$ & $0.69 \pm$ & $64.31 \pm$ & $423.72 \pm$ & $6.60 \pm$ \\
\hline & 8.78 & 0.30 & 0.06 & 1.52 & 12.46 & $0.10 a$ & $2.90 \mathrm{~b}$ & $0.11 b$ & $0.02 c$ & $1.56 a$ & $11.63 a$ & 0.20 \\
\hline \multirow[t]{2}{*}{ Exo-Pv } & $419.01 \pm$ & $9.47 \pm$ & $1.70 \pm$ & 44.26 & $246.27 \pm$ & $5.56 \pm$ & $307.17 \pm$ & $5.82 \pm$ & $1.01 \pm$ & $52.91 \pm$ & $304.50 \pm$ & $5.78 \pm$ \\
\hline & 3.41 & 0.09 & 0.03 & \pm 0.55 & 6.06 & $0.09 b$ & $6.73 a$ & $0.15 a$ & $0.03 a$ & $2.29 b$ & $8.29 c$ & 0.20 \\
\hline
\end{tabular}

Notes: E, early replacement succession field soil. M, middle replacement succession field soil. L, later replacement succession field soil. Exo, exotic species field soil. Exo-Sv, Exo-Bi and Exo-Pv, field exotic species (Exo) soil in pots were grown for Setaria viridis (Sv), Bothriochloa ischaemum (Bi) and Panicum virgatum $(\mathrm{Pv})$, respectively. Different letters indicate significant differences among groups based on Duncan's post hoc test $(P<0.05)$.

Table 3 Mean ( \pm SE) of plant carbon, nitrogen, and phosphorus concentrations and stoichiometry of the three native plant species, Setaria viridis (Sv), Artemisia gmelinii (Ag), and Bothriochloa ischaemum (Bi), planted in soils of different origin. 


\begin{tabular}{|c|c|c|c|c|c|c|c|c|c|c|c|c|c|}
\hline \multirow[t]{2}{*}{ Species } & \multirow{2}{*}{$\begin{array}{l}\text { Soil } \\
\text { origin }\end{array}$} & \multicolumn{6}{|l|}{ Shoot } & \multicolumn{6}{|l|}{ Root } \\
\hline & & $\begin{array}{l}\text { Carbon } \\
\rrbracket g / k g \rrbracket\end{array}$ & $\begin{array}{l}\text { Nitrogen } \\
\bigotimes g / k g \rrbracket\end{array}$ & $\begin{array}{l}\text { Phosphorus } \\
\rrbracket g / k g \rrbracket\end{array}$ & C:N & C:P & $\mathrm{N}: \mathrm{P}$ & $\begin{array}{l}\text { Carbon } \\
\rrbracket g / k g \rrbracket\end{array}$ & $\begin{array}{l}\text { Nitrogen } \\
\rrbracket g / k g \rrbracket\end{array}$ & $\begin{array}{l}\text { Phosphorus } \\
\rrbracket g / k g \rrbracket\end{array}$ & $\mathrm{C}: \mathrm{N}$ & C:P & $\mathrm{N}$ \\
\hline \multirow[t]{4}{*}{ Sv } & $E$ & $456.99 \pm$ & $9.00 \pm$ & $0.75 \pm$ & $51.35 \pm$ & $613.79 \pm$ & $12.09 \pm$ & $418.49 \pm$ & $6.52 \pm$ & $0.68 \pm$ & $64.84 \pm$ & $619.50 \pm$ & 9. \\
\hline & & $8.27^{* \star}$ & $0.58^{*}$ & $0.02^{\star \star \star}$ & 3.08 & $26.53^{*}$ & 0.91 & 20.27 & 0.29 & $0.01 * *$ & 5.34 & $26.77^{*}$ & 0. \\
\hline & Exo & $408.57 \pm$ & $7.17 \pm$ & $0.56 \pm$ & $57.12 \pm$ & $736.94 \pm$ & $12.95 \pm$ & $408.36 \pm$ & $5.74 \pm$ & $0.44 \pm$ & $71.28 \pm$ & $935.66 \pm$ & $1:$ \\
\hline & & 7.61 & 0.25 & 0.02 & 1.67 & 31.06 & 0.77 & 13.41 & 0.11 & 0.03 & 3.18 & 75.25 & 0 . \\
\hline \multirow[t]{4}{*}{$\mathrm{Ag}$} & $M$ & $451.97 \pm$ & $17.08 \pm$ & $1.55 \pm$ & $26.55 \pm$ & $293.76 \pm$ & $11.05 \pm$ & $441.85 \pm$ & $7.00 \pm$ & $1.33 \pm$ & $64.29 \pm$ & $334.07 \pm$ & 5. \\
\hline & & $0.57 *$ & $0.62^{*}$ & $0.08^{* *}$ & 0.91 * & $14.91^{\star \star}$ & $0.27 \star \star$ & $10.98^{\star *}$ & 0.62 & 0.04 & 4.77 & 13.34 & 0. \\
\hline & Exo & $443.10 \pm$ & $15.19 \pm$ & $0.95 \pm$ & $29.20 \pm$ & $471.85 \pm$ & $16.14 \pm$ & $376.57 \pm$ & $5.13 \pm$ & $1.40 \pm$ & $77.97 \pm$ & $285.75 \pm$ & 4. \\
\hline & & 2.49 & 0.27 & 0.06 & 0.38 & 29.87 & 0.88 & 3.93 & 0.72 & 0.19 & 11.05 & 40.62 & 1. \\
\hline \multirow[t]{4}{*}{$\mathrm{Bi}$} & $\mathrm{L}$ & $497.70 \pm$ & $8.58 \pm$ & $0.51 \pm$ & $58.09 \pm$ & $989.78 \pm$ & $17.09 \pm$ & $336.75 \pm$ & $5.48 \pm$ & $0.36 \pm$ & $64.38 \pm$ & $937.77 \pm$ & $1 !$ \\
\hline & & 4.92 & 0.18 & $0.02^{\star}$ & 1.65 & $45.46^{*}$ & $0.96^{\star}$ & 16.49 & $0.66^{*}$ & $0.01^{\star \star}$ & $8.43^{\star}$ & $64.91 *$ & 1. \\
\hline & Exo & $501.33 \pm$ & $8.20 \pm$ & $0.62 \pm$ & $61.67 \pm$ & $822.66 \pm$ & $13.40 \pm$ & $337.91 \pm$ & $3.39 \pm$ & $0.47 \pm$ & $100.38 \pm$ & $720.65 \pm$ & 7. \\
\hline & & 7.62 & 0.46 & 0.04 & 3.28 & 51.16 & 0.90 & 9.12 & 0.19 & 0.02 & 5.86 & 29.80 & 0. \\
\hline \multirow[t]{4}{*}{ Sv } & E-Sv & $401.39 \pm$ & $16.75 \pm$ & $0.97 \pm$ & $23.98 \pm$ & $417.62 \pm$ & $17.40 \pm$ & $353.35 \pm$ & $5.98 \pm$ & $0.65 \pm$ & $59.27 \pm$ & $545.67 \pm$ & 9. \\
\hline & & $0.54^{\star *}$ & $0.27^{\star \star}$ & 0.05 & $0.36^{* * *}$ & 21.65 & 0.75 & $4.05^{\star \star}$ & 0.27 & 0.03 & 3.31 & 20.96 & 0. \\
\hline & $\mathrm{E}-\mathrm{Pv}$ & $407.36 \pm$ & $14.82 \pm$ & $0.88 \pm$ & $27.49 \pm$ & $461.91 \pm$ & $16.80 \pm$ & $322.18 \pm$ & no data & no data & no data & no data & $\mathrm{nc}$ \\
\hline & & 0.73 & 0.14 & 0.02 & 0.30 & 12.38 & 0.43 & 3.68 & & & & & \\
\hline \multirow[t]{4}{*}{$\mathrm{Ag}$} & $\mathrm{M}-\mathrm{Ag}$ & $425.25 \pm$ & $17.87 \pm$ & $1.18 \pm$ & $23.82 \pm$ & $362.77 \pm$ & $15.23 \pm$ & $387.49 \pm$ & $8.59 \pm$ & $1.12 \pm$ & $45.32 \pm$ & $348.84 \pm$ & 7. \\
\hline & & $1.17^{\star}$ & $0.35^{\star}$ & $0.06^{\star \star \star}$ & $0.43^{*}$ & $17.25^{\star \star}$ & $0.71^{\star \star}$ & $4.48^{\star *}$ & $0.30 * * *$ & $0.06^{* \star}$ & 2.04 ** & $13.83^{*}$ & 0. \\
\hline & $\mathrm{M}-\mathrm{Pv}$ & $415.85 \pm$ & $16.25 \pm$ & $0.75 \pm$ & $25.61 \pm$ & $555.53 \pm$ & $21.72 \pm$ & $344.29 \pm$ & $5.64 \pm$ & $0.88 \pm$ & $61.41 \pm$ & $393.14 \pm$ & 6. \\
\hline & & 2.47 & 0.31 & 0.03 & 0.40 & 28.25 & 1.21 & 5.65 & 0.29 & 0.03 & 2.22 & 11.18 & 0. \\
\hline \multirow[t]{4}{*}{$\mathrm{Bi}$} & L-Bi & $409.55 \pm$ & $8.76 \pm$ & $0.69 \pm$ & $46.80 \pm$ & $590.73 \pm$ & $12.64 \pm$ & $380.47 \pm$ & $5.18 \pm$ & $0.84 \pm$ & $73.43 \pm$ & $453.49 \pm$ & 6. \\
\hline & & $3.23^{* \star}$ & $0.16^{*}$ & $0.00 * \star$ & 1.19 & $4.56^{\star}$ & $0.23^{\star}$ & 0.55 & $0.04^{\star}$ & $0.01 *$ & 0.48 & 3.77 & 0. \\
\hline & L-Pv & $388.19 \pm$ & $8.01 \pm$ & $0.55 \pm$ & $48.57 \pm$ & $708.13 \pm$ & $14.60 \pm$ & $364.16 \pm$ & $2.41 \pm$ & $0.73 \pm$ & $171.75 \pm$ & $502.82 \pm$ & 3. \\
\hline & & 1.95 & 0.20 & 0.02 & 1.01 & 24.69 & 0.59 & 4.64 & 0.46 & 0.03 & 37.95 & 20.4 & 0. \\
\hline
\end{tabular}

Notes: E, early replacement succession field soil. M, middle replacement succession field soil. L, later replacement succession field soil. Exo, exotic species field soil. E-Sv and E-Pv, field E soil in pots were grown for Sv and Pv, respectively. M-Ag and M-Pv, field M soil in pots were grown for Ag and Pv, respectively. L$\mathrm{Bi}$ and $\mathrm{L}-\mathrm{Pv}$, field $\mathrm{L}$ soil in pots were grown for $\mathrm{Bi}$ and $\mathrm{Pv}$, respectively. ${ }^{*},{ }^{*}$ and $* \star *$ indicate significant differences at $P<0.05, P<0.01$, and $P<0.001$, respectively, based on the t-test. No data means that the samples were insufficient to complete a measurement.

Table 4 Mean $( \pm$ SE) of soil chemical properties in the soils created by the four plant species after the first growth period. 


\begin{tabular}{|llllll|}
\hline Soil origin & $\mathrm{SOC}\left(\mathrm{g} \mathrm{kg}^{-1}\right)$ & $\mathrm{TN}\left(\mathrm{g} \mathrm{kg}^{-1}\right)$ & $\mathrm{TP}\left(\mathrm{g} \mathrm{kg}^{-1}\right)$ & $\mathrm{AP}\left(\mathrm{mg} \mathrm{kg}^{-1}\right)$ & $\mathrm{AN}\left(\mathrm{mg} \mathrm{kg}^{-1}\right)$ \\
\hline Exo-CK & $4.91 \pm 0.02 \mathrm{~b}$ & $0.55 \pm 0.0$ & $0.57 \pm 0.02 \mathrm{a}$ & $0.99 \pm 0.08 \mathrm{~d}$ & $18.82 \pm 0.45 \mathrm{~b}$ \\
\hline Exo-Sv & $5.20 \pm 0.10 \mathrm{a}$ & $0.56 \pm 0.01$ & $0.57 \pm 0.01 \mathrm{a}$ & $1.59 \pm 0.07 \mathrm{~b}$ & $18.78 \pm 0.23 \mathrm{~b}$ \\
\hline Exo-Bi & $5.08 \pm 0.02 \mathrm{ab}$ & $0.55 \pm 0.00$ & $0.52 \pm 0.02 \mathrm{~b}$ & $1.41 \pm 0.03 \mathrm{C}$ & $14.99 \pm 0.91 \mathrm{c}$ \\
\hline Exo-Pv & $5.23 \pm 0.06 \mathrm{a}$ & $0.56 \pm 0.01$ & $0.57 \pm 0.01 \mathrm{a}$ & $1.71 \pm 0.01 \mathrm{a}$ & $21.82 \pm 0.36 \mathrm{a}$ \\
\hline E-CK & $5.17 \pm 0.14 \mathrm{~b}$ & $0.59 \pm 0.01 \mathrm{~b}$ & $0.50 \pm 0.01 \mathrm{~b}$ & $1.16 \pm 0.110 \mathrm{~b}$ & $20.13 \pm 0.18 \mathrm{c}$ \\
\hline E-Sv & $5.68 \pm 0.06 \mathrm{a}$ & $0.63 \pm 0.01 \mathrm{a}$ & $0.54 \pm 0.01 \mathrm{a}$ & $1.56 \pm 0.06 \mathrm{a}$ & $23.22 \pm 0.27 \mathrm{a}$ \\
\hline E-Pv & $5.29 \pm 0.10 \mathrm{~b}$ & $0.62 \pm 0.01 \mathrm{a}$ & $0.51 \pm 0.01 \mathrm{~b}$ & $1.18 \pm 0.14 \mathrm{~b}$ & $21.85 \pm 0.49 \mathrm{~b}$ \\
\hline M-CK & $4.75 \pm 0.19 \mathrm{~b}$ & $0.57 \pm 0.01 \mathrm{ab}$ & $0.56 \pm 0.01 \mathrm{ab}$ & $0.84 \pm 0.03 \mathrm{c}$ & $29.06 \pm 0.15 \mathrm{c}$ \\
\hline M-Ag & $5.16 \pm 0.04 \mathrm{a}$ & $0.59 \pm 0.01 \mathrm{a}$ & $0.58 \pm 0.00 \mathrm{a}$ & $1.65 \pm 0.05 \mathrm{a}$ & $33.96 \pm 0.10 \mathrm{a}$ \\
\hline M-Pv & $5.01 \pm 0.06 \mathrm{ab}$ & $0.55 \pm 0.01 \mathrm{~b}$ & $0.53 \pm 0.013 \mathrm{~b}$ & $1.01 \pm 0.04 \mathrm{~b}$ & $31.15 \pm 0.33 \mathrm{~b}$ \\
\hline L-CK & $4.58 \pm 0.06 \mathrm{~b}$ & $0.51 \pm 0.01$ & $0.47 \pm 0.01$ & $0.98 \pm 0.09 \mathrm{~b}$ & $29.21 \pm 0.59 \mathrm{c}$ \\
\hline L-Bi & $5.06 \pm 0.08 \mathrm{a}$ & $0.53 \pm 0.01$ & $0.46 \pm 0.01$ & $1.77 \pm 0.06 \mathrm{a}$ & $34.05 \pm 0.38 \mathrm{a}$ \\
\hline L-Pv & $4.89 \pm 0.06 \mathrm{ab}$ & $0.52 \pm 0.01$ & $0.45 \pm 0.01$ & $0.79 \pm 0.07 \mathrm{~b}$ & $30.65 \pm 0.23 \mathrm{~b}$ \\
\hline
\end{tabular}

Notes: Exo-CK, E-CK, M-CK, and L-CK, no plants were prepared. Exo-Sv, Exo-Bi, and Exo-Pv, field Exo soil in pots were grown for Setaria viridis (Sv), Bothriochloa ischaemum (Bi), and Panicum virgatum (Pv), respectively. E-Sv and E-Pv, field E soil in pots were grown for Sv and Pv, respectively. M-Ag and M-Pv, field M soil in pots was grown for $\mathrm{Ag}$ and $\mathrm{PV}$, respectively. $\mathrm{L}-\mathrm{Bi}$ and $\mathrm{L}-\mathrm{PV}$, field $\mathrm{L}$ soil in pots were grown for $\mathrm{Bi}$ and $\mathrm{Pv}$, respectively. SOC, soil organic carbon. TN, soil total nitrogen. TP, soil total phosphorus. AP, soil available phosphorus. AN, soil available nitrogen. Different letters indicate significant differences among groups based on Duncan's post hoc test $(P<0.05)$.

Table 5 Mean $( \pm$ SE) of soil biological properties in the soils created from the four plant species after the first growth period.

\begin{tabular}{|c|c|c|c|c|c|c|c|c|c|}
\hline $\begin{array}{l}\text { Soil } \\
\text { origin }\end{array}$ & $\mathrm{MBC}\left(\mathrm{mg} \mathrm{kg}^{-1}\right)$ & $\begin{array}{l}\text { MBN (mg } \\
\left.\mathrm{kg}^{-1}\right)\end{array}$ & $\begin{array}{l}\text { B-G }\left(\mu \mathrm{mol} \mathrm{h}^{-}\right. \\
\left.{ }^{1} \mathrm{~g}^{-1}\right)\end{array}$ & $\begin{array}{l}\text { N-AG }(\mu \mathrm{mol} \\
\left.\mathrm{h}^{-1} \mathrm{~g}^{-1}\right)\end{array}$ & $\begin{array}{l}\text { A-P }\left(\mu \mathrm{mol} \mathrm{h}^{-}\right. \\
\left.{ }^{1} \mathrm{~g}^{-1}\right)\end{array}$ & $\begin{array}{l}\text { Bacteria } \\
\text { richness }\end{array}$ & $\begin{array}{l}\text { Bacteria } \\
\text { diversity }\end{array}$ & Fungi richness & $\begin{array}{l}\text { Fungi } \\
\text { diversity }\end{array}$ \\
\hline $\begin{array}{l}\text { Exo- } \\
\text { CK }\end{array}$ & $205.70 \pm 16.87 c$ & $12.19 \pm 1.19 c$ & $1.96 \pm 0.04 b$ & $4.09 \pm 0.03 c$ & $10.4 \pm 0.23 d$ & $1950.16 \pm 11.98$ & $6.36 \pm 0.05 b$ & $573.56 \pm$ & $2.55 \pm 0.71$ \\
\hline $\begin{array}{l}\text { Exo- } \\
\text { Sv }\end{array}$ & $231.20 \pm 3.26 b$ & $22.02 \pm 0.78 b$ & $2.53 \pm 0.04 a b$ & $4.17 \pm 0.03 b c$ & $12.24 \pm 0.05 b$ & $1939.81 \pm 6.62$ & $6.48 \pm 0.02 a$ & $703.95 \pm 7.66 a$ & $3.18 \pm 0.31$ \\
\hline $\begin{array}{l}\text { Exo- } \\
\mathrm{Bi}\end{array}$ & $245.00 \pm 8.34 b$ & $20.97 \pm 0.39 b$ & $2.05 \pm 0.00 \mathrm{~b}$ & $4.28 \pm 0.09 b$ & $11.48 \pm 0.21 c$ & $1944.45 \pm 4.80$ & $6.52 \pm 0.01 a$ & $670.65 \pm 8.68 a$ & $3.26 \pm 0.33$ \\
\hline $\begin{array}{l}\text { Exo- } \\
\text { Pv }\end{array}$ & $292.25 \pm 5.07 a$ & $24.66 \pm 0.54 a$ & $2.62 \pm 0.04 a$ & $4.98 \pm 0.06 a$ & $13.69 \pm 0.14 a$ & $1937.17 \pm 14.83$ & $6.48 \pm 0.02 a$ & $655.02 \pm 4.36 a$ & $3.15 \pm 0.11$ \\
\hline E-CK & $151.68 \pm 1.68 b$ & $21.17 \pm 0.74 c$ & $1.88 \pm 0.04 b$ & $3.23 \pm 0.01 b$ & $7.97 \pm 0.17 \mathrm{c}$ & $1934.73 \pm 4.03$ & $6.49 \pm 0.04$ & $687.83 \pm 9.79$ & $4.36 \pm 0.15 a$ \\
\hline E-Sv & $165.40 \pm 2.96 a$ & $31.55 \pm 1.54 a$ & $2.21 \pm 0.09 a$ & $3.83 \pm 0.11 a$ & $11.54 \pm 0.08 a$ & $1935.91 \pm 11.18$ & $6.50 \pm 0.04$ & $567.49 \pm 108.27$ & $3.66 \pm 0.26 b$ \\
\hline $\mathrm{E}-\mathrm{PV}$ & $152.89 \pm 0.99 b$ & $23.23 \pm 1.28 b$ & $2.01 \pm 0.04 b$ & $3.3 \pm 0.05 b$ & $9.38 \pm 0.14 b$ & $1930.09 \pm 6.02$ & $6.52 \pm 0.03$ & $672.06 \pm 16.54$ & $3.87 \pm 0.15 a b$ \\
\hline M-CK & $171.85 \pm 5.74 \mathrm{c}$ & $21.03 \pm 1.00 \mathrm{c}$ & $2.24 \pm 0.02 b$ & $1.21 \pm 0.03 b$ & $1.19 \pm 0.01 \mathrm{a}$ & $1944.90 \pm 8.47$ & $6.49 \pm 0.02$ & $622.73 \pm 39.37$ & $3.71 \pm 0.40$ \\
\hline $\mathrm{M}-\mathrm{Ag}$ & $232.95 \pm 8.85 a$ & $32.71 \pm 1.05 a$ & $4.18 \pm 0.37 a$ & $4.53 \pm 0.08 a$ & $1.31 \pm 0.08 a$ & $1931.71 \pm 8.90$ & $6.54 \pm 0.01$ & $652.14 \pm 26.68$ & $4.29 \pm 0.15$ \\
\hline $\mathrm{M}-\mathrm{Pv}$ & $195.65 \pm 7.81 b$ & $26.65 \pm 0.75 b$ & $2.33 \pm 0.03 b$ & $4.36 \pm 0.05 a$ & $1.26 \pm 0.02 a$ & $1942.12 \pm 9.06$ & $6.54 \pm 0.03$ & $695.21 \pm 6.76$ & $4.17 \pm 0.15$ \\
\hline L-CK & $102.90 \pm 7.95 b$ & $19.13 \pm 1.04 b$ & $1.48 \pm 0.02 b$ & $1.57 \pm 0.01 b$ & $8.67 \pm 0.07 b$ & $1921.29 \pm 20.10$ & $6.40 \pm 0.04$ & $585.15 \pm 23.00 b$ & $4.15 \pm 0.15$ \\
\hline L-Bi & $157.16 \pm 5.42 a$ & $24.48 \pm 0.75 a$ & $1.77 \pm 0.07 a$ & $1.96 \pm 0.06 a$ & $9.33 \pm 0.10 \mathrm{a}$ & $1957.62 \pm 3.10$ & $6.40 \pm 0.03$ & $690.88 \pm 8.03 a$ & $4.66 \pm 0.11$ \\
\hline$L-P v$ & $106.65 \pm 1.78 b$ & $23.68 \pm 0.68 a$ & $1.56 \pm 0.04 b$ & $1.64 \pm 0.05 b$ & $9.05 \pm 0.11 b$ & $1908.37 \pm 38.10$ & $6.39 \pm 0.07$ & $694.61 \pm 11.61 a$ & $4.49 \pm 0.25$ \\
\hline
\end{tabular}

Notes: Exo-CK, E-CK, M-CK, and L-CK, no plants were prepared. Exo-Sv, Exo-Bi, and Exo-Pv, field Exo soil in pots were grown for Setaria viridis (Sv), Bothriochloa ischaemum (Bi), and Panicum virgatum (Pv), respectively. E-Sv and E-Pv, field E soil in pots were grown for Sv and Pv, respectively. M-Ag and M-Pv, field M soil in pots was grown for $\mathrm{Ag}$ and $\mathrm{Pv}$, respectively. $\mathrm{L}-\mathrm{Bi}$ and $\mathrm{L}-\mathrm{Pv}$, field $\mathrm{L}$ soil in pots were grown for $\mathrm{Bi}$ and $\mathrm{PV}$, respectively. MBC, soil microbial biomass carbon. MBN, soil microbial biomass nitrogen. B-G, $\beta$-1,4-glucosidase. N-AG, N-acetyl- $\beta$-D-glucosaminidase. A-P, acid phosphatase. Bacteria and fungi richness were calculated based on Chao1 index. Bacteria and fungi diversity were calculated based on Shannon index. Different letters indicate significant differences among groups based on Duncan's post hoc test $(P<0.05)$. 
Figures
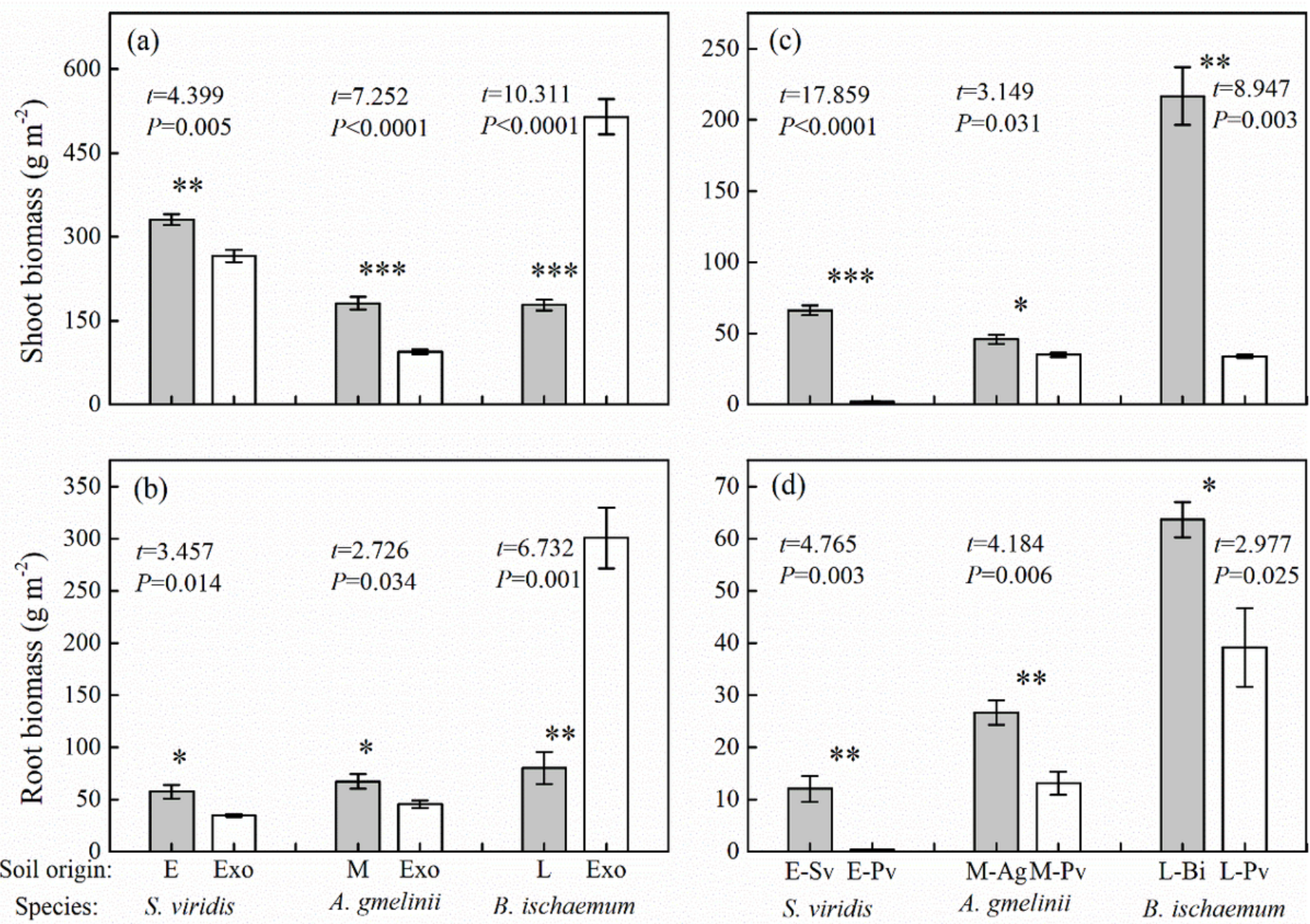

Figure 1

Mean $( \pm$ SE) $(n=4)$ of (a) shoot biomass and (b) root biomass of exotic species Panicum virgatum (Pv) growing in pots with the soils from early replacement succession (E), middle replacement succession (M), later replacement succession ( $L$ ), and exotic species (Exo); Mean ( \pm SE) of (c) shoot biomass and (d) root biomass of exotic species Panicum virgatum (Pv) growing in pots with soil created from the three native species of early replacement succession Setaria viridis (Sv), middle replacement succession Artemisia gmelinii ( $\mathrm{Ag}$ ) and later replacement succession Bothriochloa ischaemum (Bi), and exotic species $\mathrm{Pv}$ that originated from Exo field soils. Different letters indicate significant differences among groups based on Duncan's post hoc test $(P<0.05)$. No data means that pots was accidentally damaged during planting. 

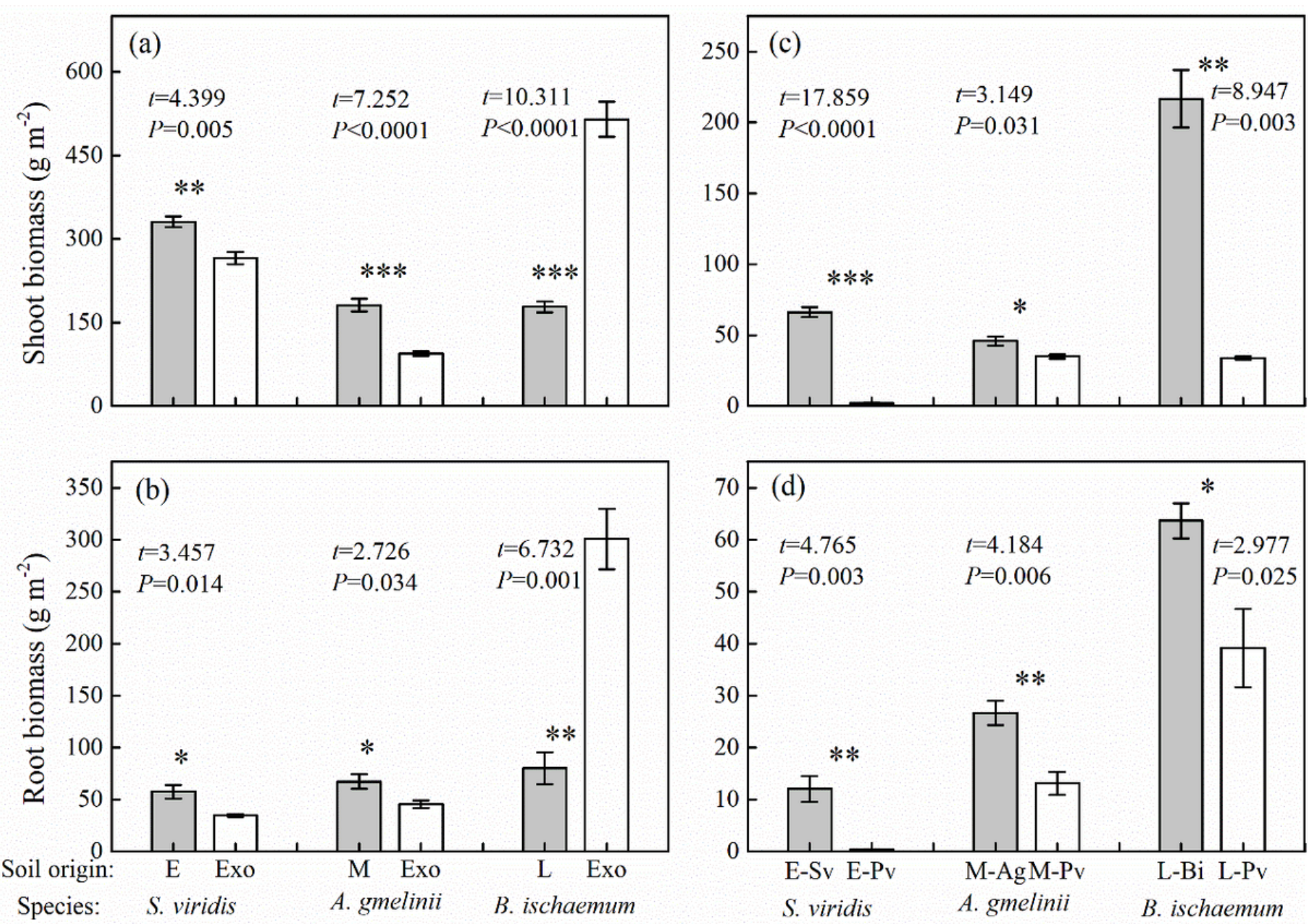

\section{Figure 1}

Mean $( \pm$ SE) $(n=4)$ of $(a)$ shoot biomass and (b) root biomass of exotic species Panicum virgatum (Pv) growing in pots with the soils from early replacement succession (E), middle replacement succession (M), later replacement succession ( $L$ ), and exotic species (Exo); Mean ( \pm SE) of (c) shoot biomass and (d) root biomass of exotic species Panicum virgatum (Pv) growing in pots with soil created from the three native species of early replacement succession Setaria viridis (Sv), middle replacement succession Artemisia gmelinii (Ag) and later replacement succession Bothriochloa ischaemum (Bi), and exotic species $\mathrm{Pv}$ that originated from Exo field soils. Different letters indicate significant differences among groups based on Duncan's post hoc test $(P<0.05)$. No data means that pots was accidentally damaged during planting. 

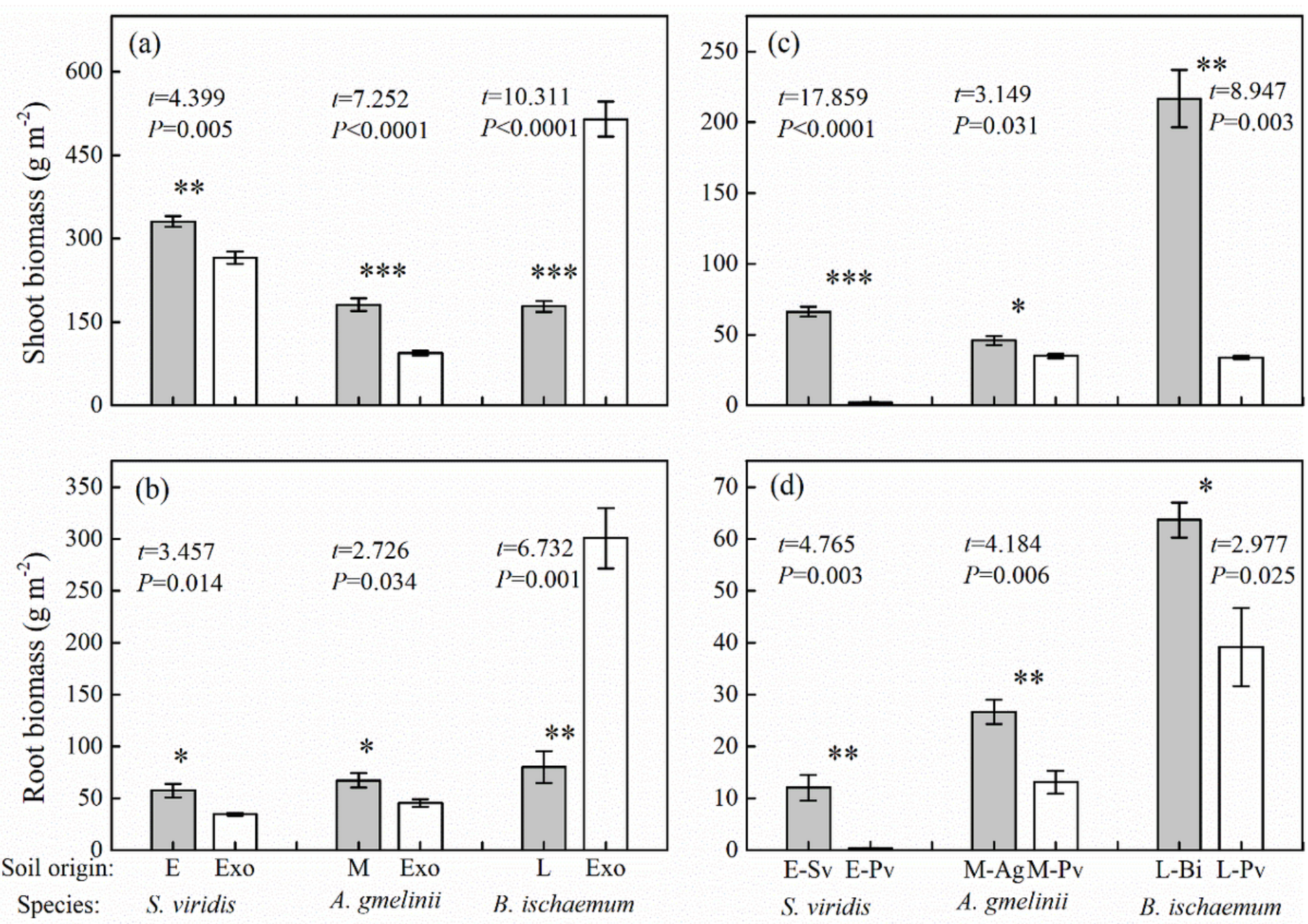

\section{Figure 1}

Mean $( \pm$ SE) $(n=4)$ of $(a)$ shoot biomass and (b) root biomass of exotic species Panicum virgatum (Pv) growing in pots with the soils from early replacement succession (E), middle replacement succession (M), later replacement succession ( $L$ ), and exotic species (Exo); Mean ( \pm SE) of (c) shoot biomass and (d) root biomass of exotic species Panicum virgatum (Pv) growing in pots with soil created from the three native species of early replacement succession Setaria viridis (Sv), middle replacement succession Artemisia gmelinii (Ag) and later replacement succession Bothriochloa ischaemum (Bi), and exotic species $\mathrm{Pv}$ that originated from Exo field soils. Different letters indicate significant differences among groups based on Duncan's post hoc test $(P<0.05)$. No data means that pots was accidentally damaged during planting. 
Species:
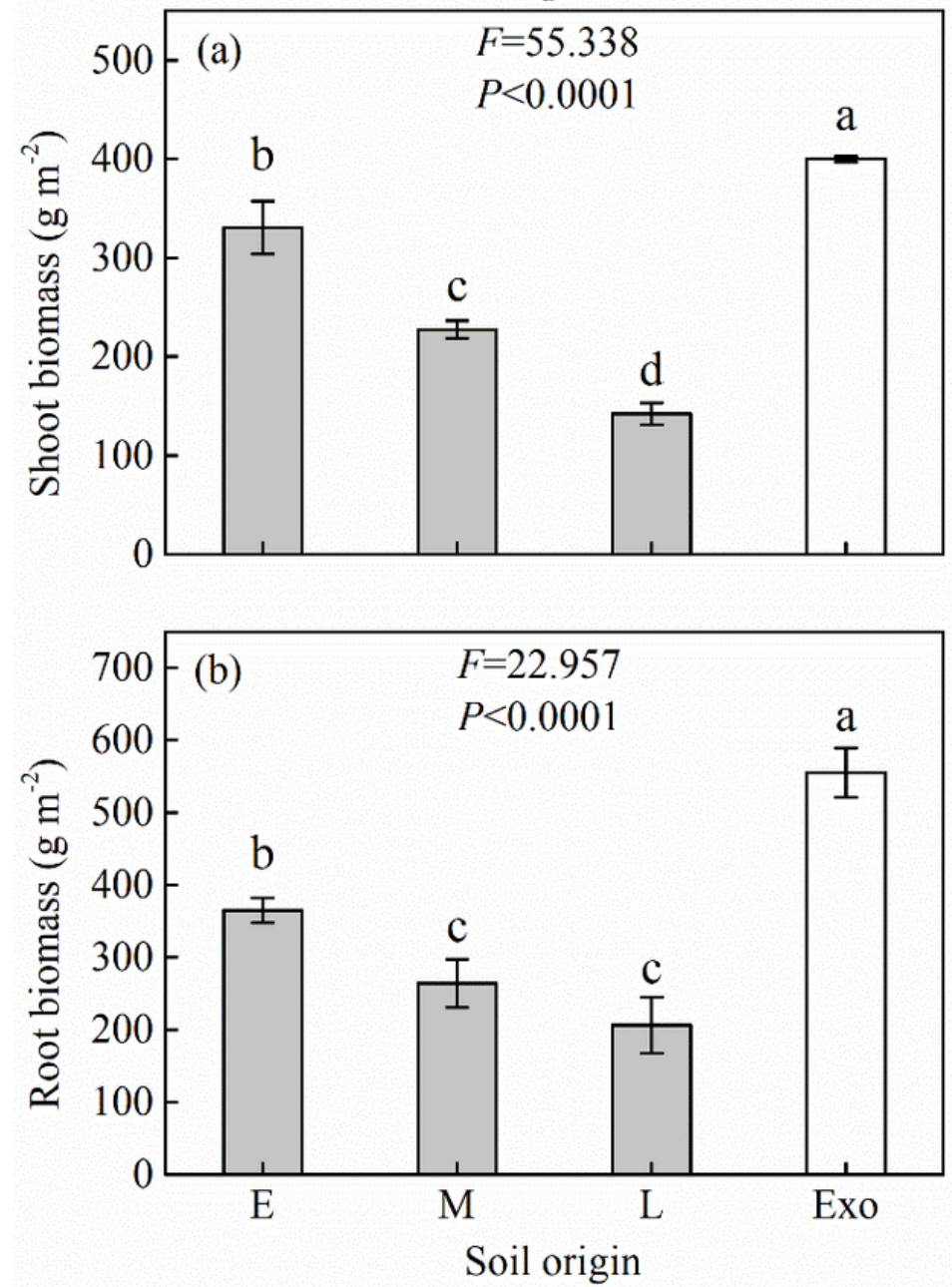

P. virgatum

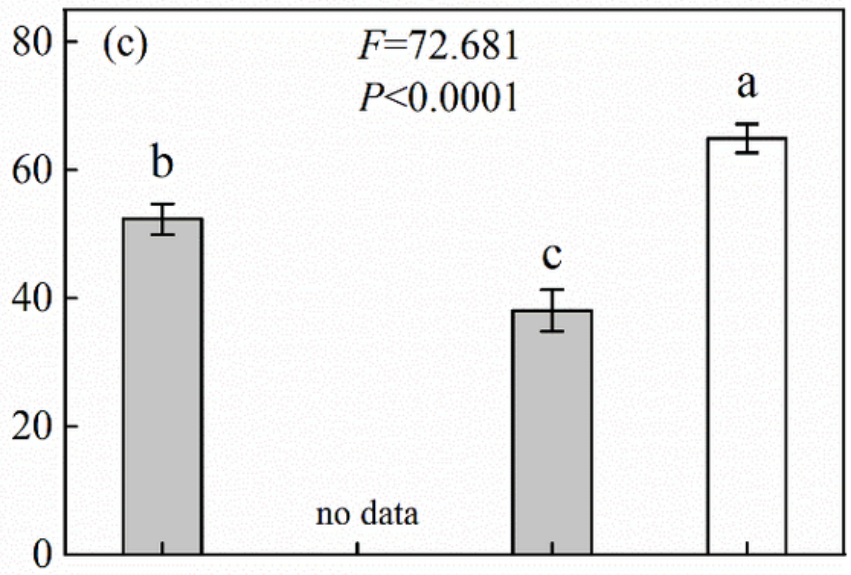

(d)

$F=62.502$

$40-\quad \mathrm{b} \quad P<0.0001$

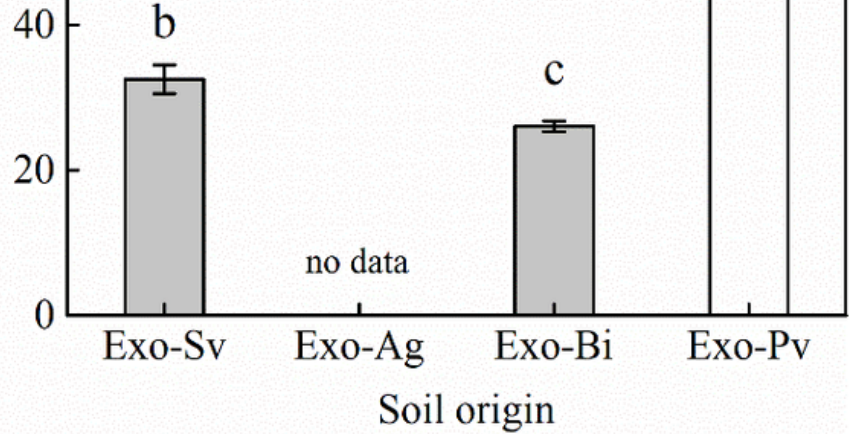

Figure 2

Mean $( \pm$ SE) $(n=4)$ of $(a)$ shoot biomass and (b) root biomass of Setaria viridis (Sv) grown in pots with the field soil of early replacement succession (E) and exotic species (Exo), Artemisia gmelinii (Ag) grown in pots with the field soil of middle replacement succession (M) and Exo, and Bothriochloa ischaemum (Bi) grown in pots with the field soil of later replacement succession (L) and Exo; Mean ( \pm SE) of (c) shoot biomass and (d) root biomass of Setaria viridis (Sv) grown in pots with soils created from Sv and Panicum virgatum (Pv) originating from early replacement succession (E) field soil, Artemisia gmelinii (Ag) grown in pots with soils created from $\mathrm{Ag}$ and $\mathrm{Pv}$ originating from middle replacement succession $(\mathrm{M})$ field soil, and Bothriochloa ischaemum (Bi) grown in pots with soils created from $\mathrm{Bi}$ and $\mathrm{Pv}$ originating from later replacement succession $(\mathrm{L})$. Notes: ${ }^{*}{ }^{* \star}$ and ${ }^{*} *$ indicate significant differences at $\mathrm{P}<0.05$, $\mathrm{P}<$ 0.01 and $P<0.001$, respectively based on the t-test. 
Species:
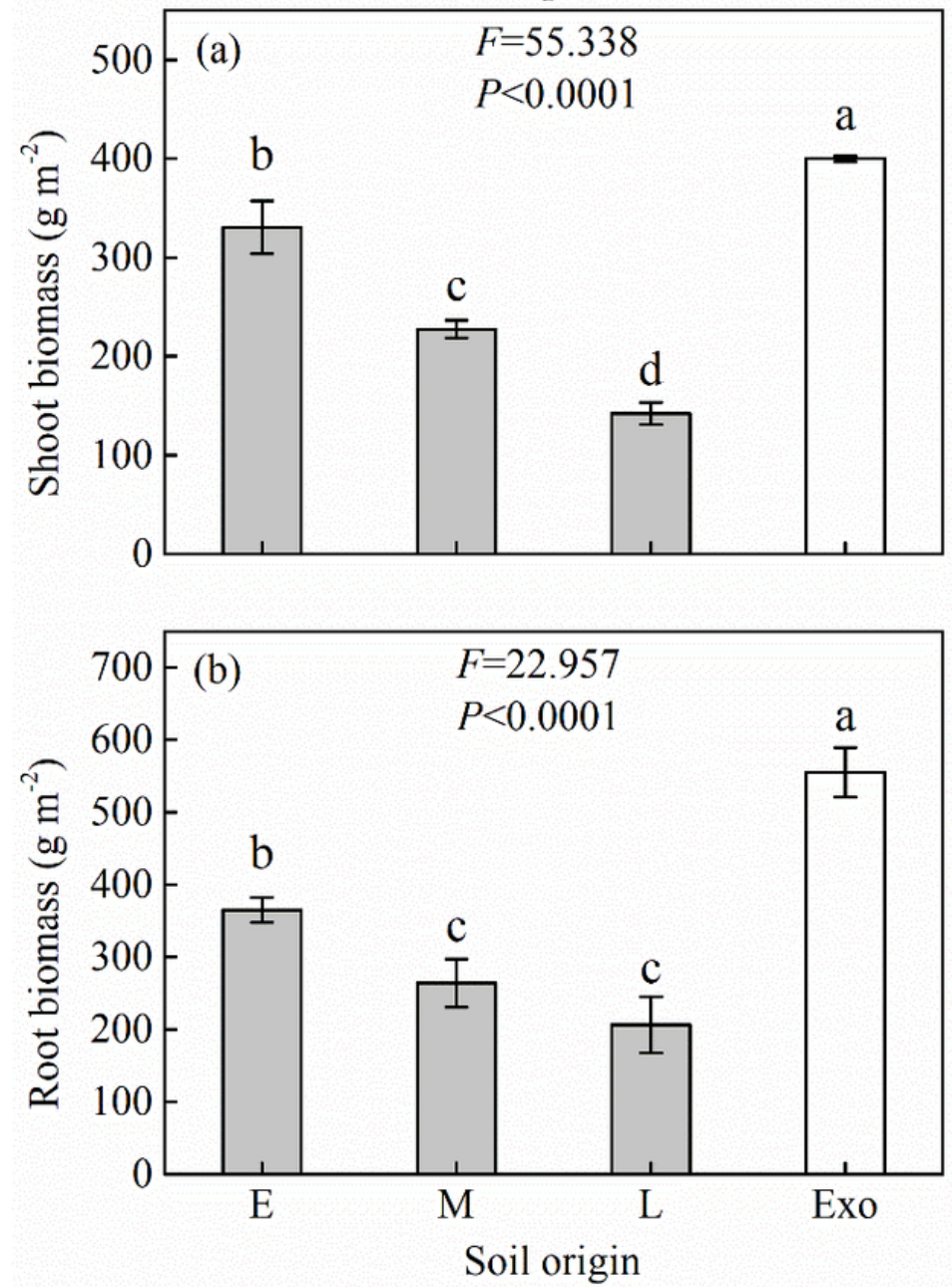

P. virgatum
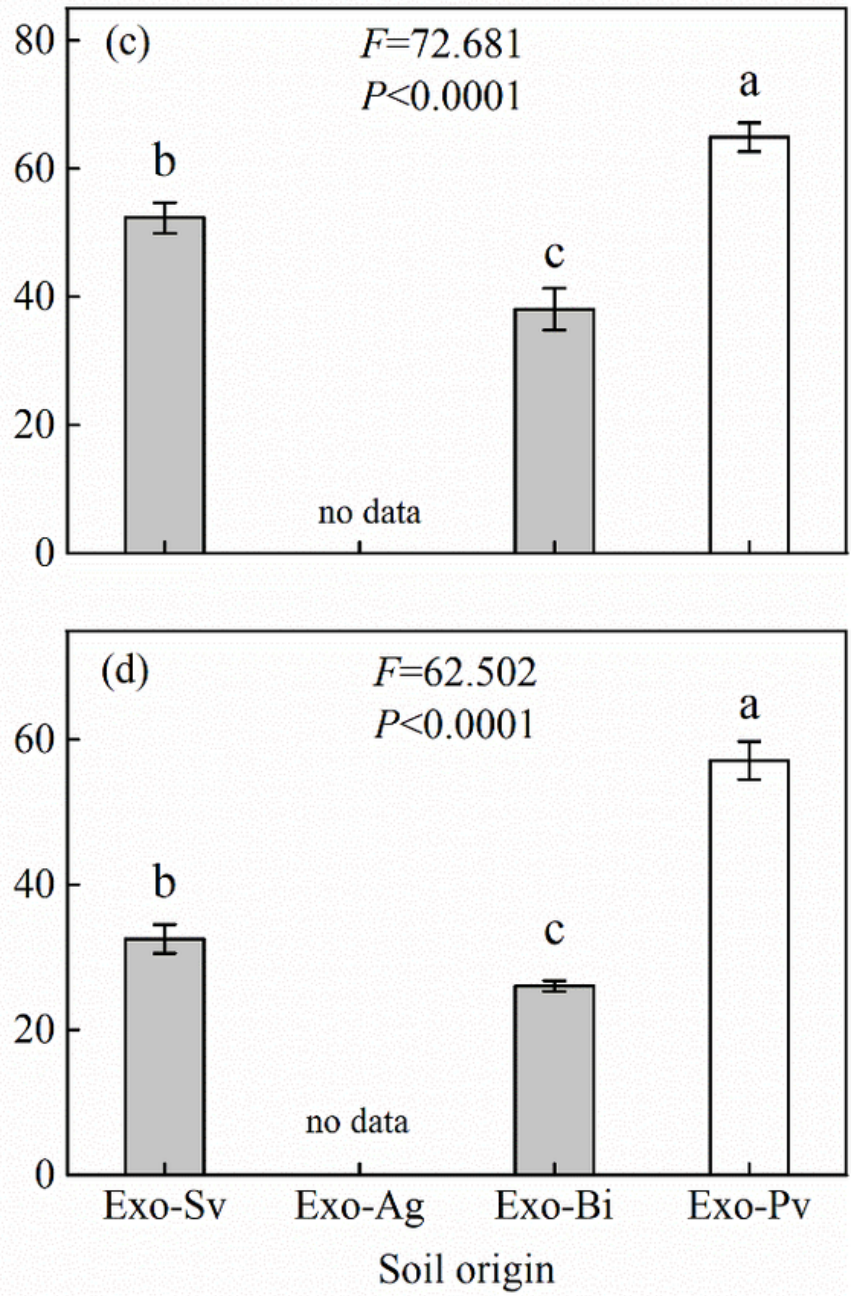

\section{Figure 2}

Mean $( \pm$ SE) $(n=4)$ of (a) shoot biomass and (b) root biomass of Setaria viridis (Sv) grown in pots with the field soil of early replacement succession (E) and exotic species (Exo), Artemisia gmelinii (Ag) grown in pots with the field soil of middle replacement succession (M) and Exo, and Bothriochloa ischaemum (Bi) grown in pots with the field soil of later replacement succession (L) and Exo; Mean ( \pm SE) of (c) shoot biomass and (d) root biomass of Setaria viridis (Sv) grown in pots with soils created from Sv and Panicum virgatum (Pv) originating from early replacement succession (E) field soil, Artemisia gmelinii (Ag) grown in pots with soils created from $\mathrm{Ag}$ and $\mathrm{Pv}$ originating from middle replacement succession (M) field soil, and Bothriochloa ischaemum (Bi) grown in pots with soils created from $\mathrm{Bi}$ and $\mathrm{Pv}$ originating from later replacement succession $(\mathrm{L})$. Notes: ${ }^{*}{ }^{* \star}$ and ${ }^{*} *$ indicate significant differences at $\mathrm{P}<0.05$, $\mathrm{P}<$ 0.01 and $P<0.001$, respectively based on the t-test. 
Species:
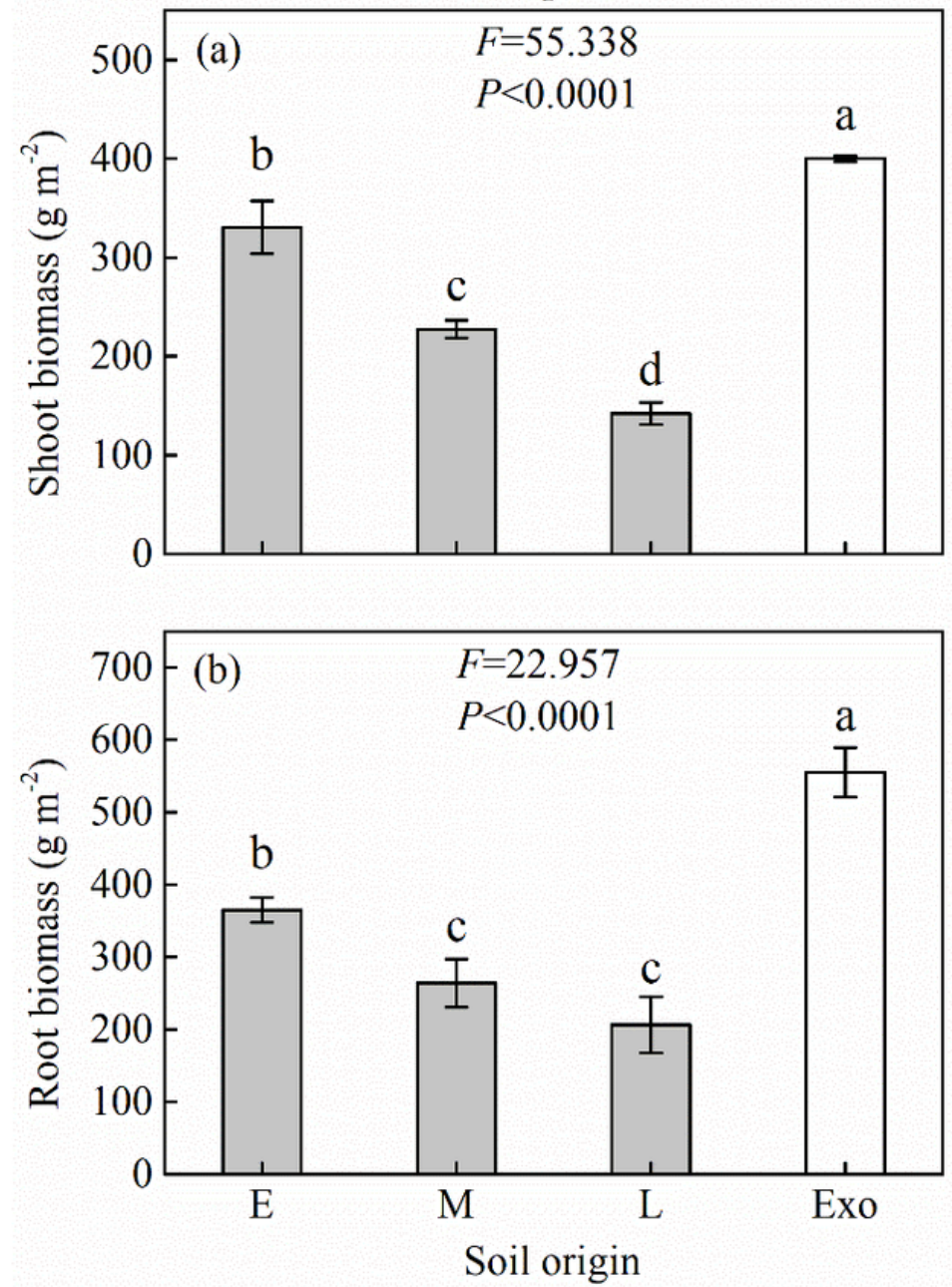

P. virgatum
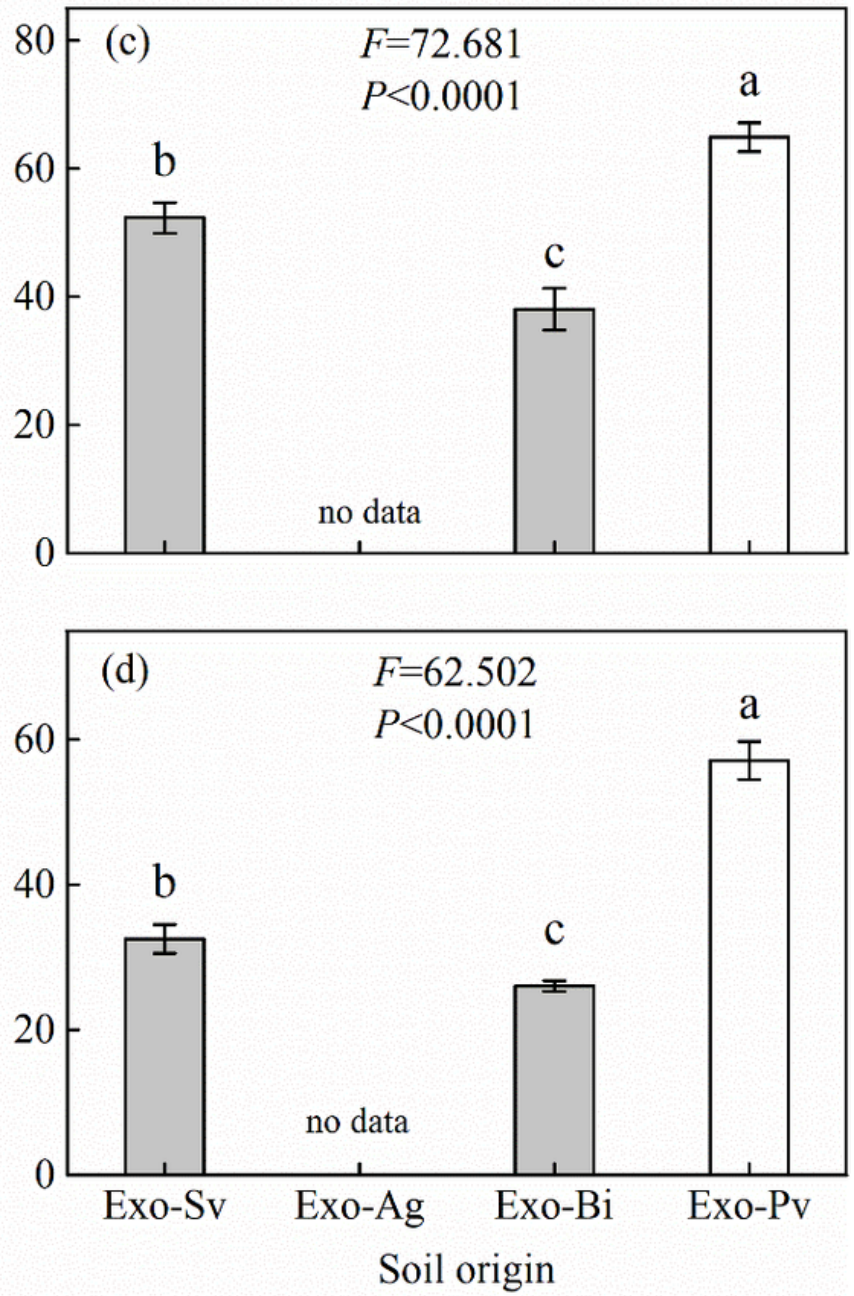

\section{Figure 2}

Mean $( \pm$ SE) $(n=4)$ of (a) shoot biomass and (b) root biomass of Setaria viridis (Sv) grown in pots with the field soil of early replacement succession (E) and exotic species (Exo), Artemisia gmelinii (Ag) grown in pots with the field soil of middle replacement succession (M) and Exo, and Bothriochloa ischaemum (Bi) grown in pots with the field soil of later replacement succession (L) and Exo; Mean ( \pm SE) of (c) shoot biomass and (d) root biomass of Setaria viridis (Sv) grown in pots with soils created from Sv and Panicum virgatum (Pv) originating from early replacement succession (E) field soil, Artemisia gmelinii (Ag) grown in pots with soils created from $\mathrm{Ag}$ and $\mathrm{Pv}$ originating from middle replacement succession (M) field soil, and Bothriochloa ischaemum (Bi) grown in pots with soils created from $\mathrm{Bi}$ and $\mathrm{Pv}$ originating from later replacement succession $(\mathrm{L})$. Notes: ${ }^{*}{ }^{* \star}$ and ${ }^{*} *$ indicate significant differences at $\mathrm{P}<0.05$, $\mathrm{P}<$ 0.01 and $P<0.001$, respectively based on the t-test. 

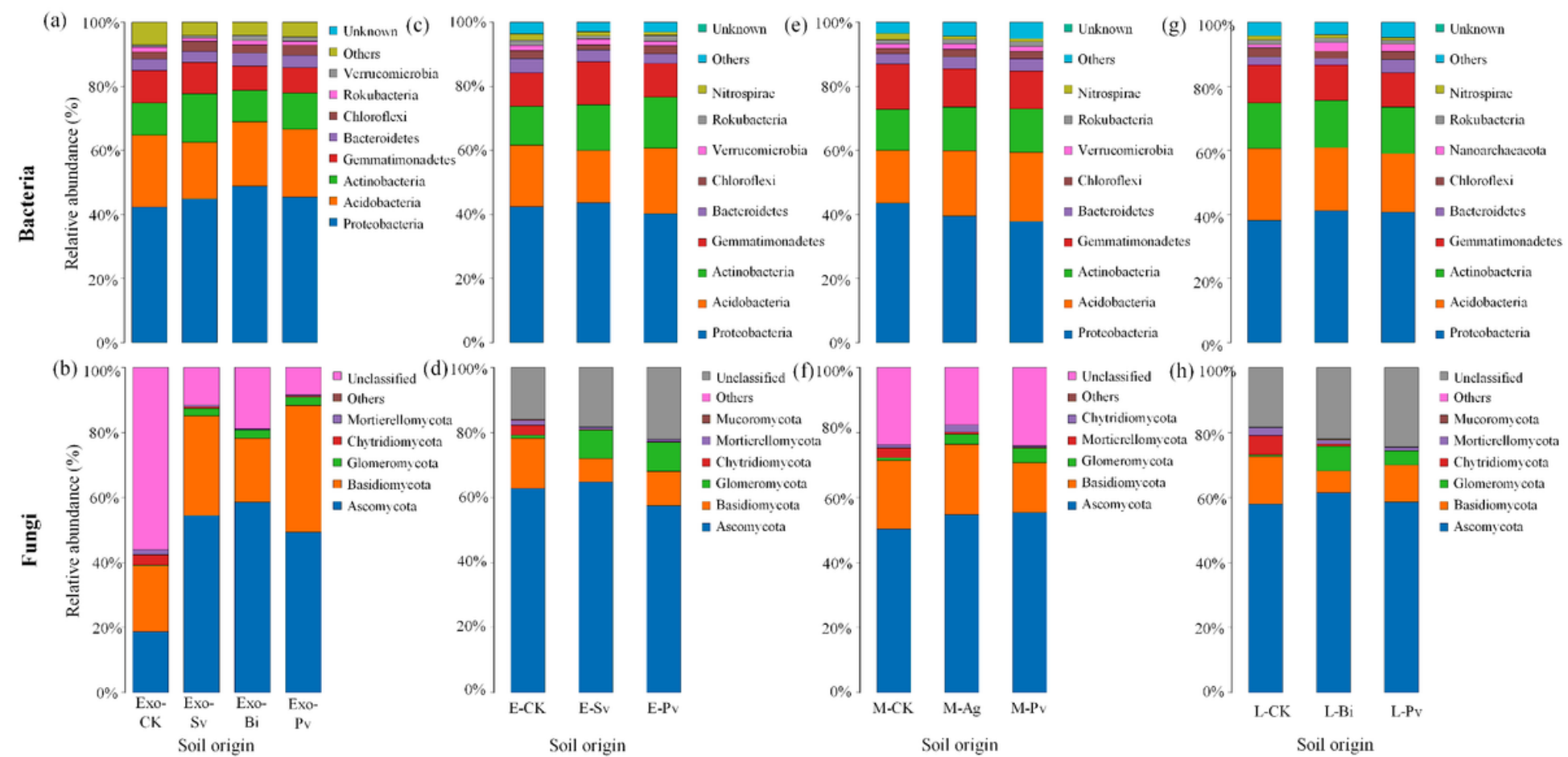

(d) $100 \%$

- Unclassificd (f)100\%

$$
\text { Others }
$$

- Mucoromycota $80 \%$
- Morticrellomycota

an Corticridiomycota

- Glomeromicota

n Basidiomycota

n Ascomycota

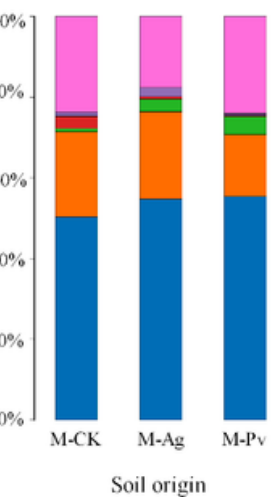

Unclassified (h) 100

- Others

- Chytridiomycota
- Morticrellomycota $80 \%$

- Glomeromycota

nasidiomycota

- Ascomycota

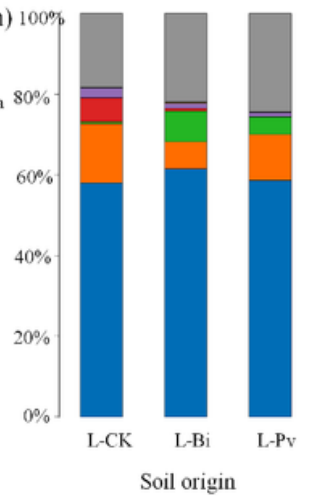

- Unclassificd

athers

- Mucoromycota

- Morticrellomycot

- Chytridiomycota

- Glomeromy cota

- Basidiomycota

- Ascomycota

Figure 3

Relative abundance of soil bacteria $(a, c, e, g)$ and fungi $(b, d, f, h)$ at the phylum level $(n=4)$. Notes: Exo-CK, field exotic species (Exo) soil in pots was not planted. Exo-CK, E-CK, M-CK, and L-CK, no plants were prepared. Exo-Sv, Exo-Bi, and Exo-Pv, field Exo soil in pots were grown for Setaria viridis (Sv), Bothriochloa ischaemum (Bi), and Panicum virgatum (Pv), respectively. E-Sv and E-Pv, field E soil in pots were grown for Sv and Pv, respectively. M-Ag and M-Pv, field $\mathrm{M}$ soil in pots was grown for $\mathrm{Ag}$ and $\mathrm{Pv}$, respectively. $\mathrm{L}-\mathrm{Bi}$ and $\mathrm{L}-\mathrm{Pv}$, field $\mathrm{L}$ soil in pots were grown for $\mathrm{Bi}$ and $\mathrm{Pv}$, respectively.

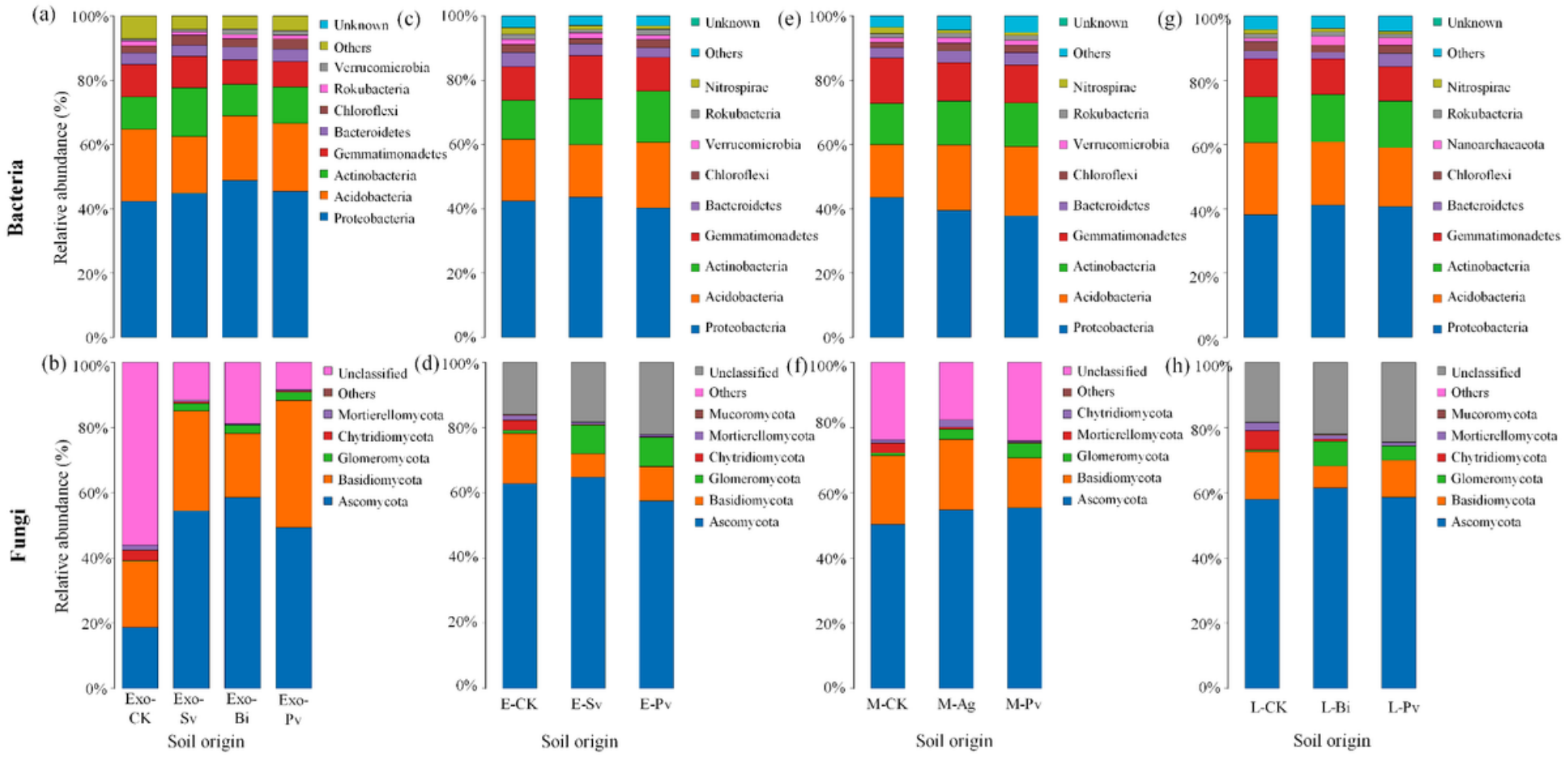

Figure 3

Relative abundance of soil bacteria $(a, c, e, g)$ and fungi $(b, d, f, h)$ at the phylum level $(n=4)$. Notes: Exo-CK, field exotic species (Exo) soil in pots was not planted. Exo-CK, E-CK, M-CK, and L-CK, no plants were prepared. Exo-Sv, Exo-Bi, and Exo-Pv, field Exo soil in pots were grown for Setaria viridis (Sv), Bothriochloa ischaemum (Bi), and Panicum virgatum (Pv), respectively. E-Sv and E-Pv, field E soil in pots were grown for Sv and Pv, respectively. M-Ag and M-Pv, field $\mathrm{M}$ soil in pots was grown for $\mathrm{Ag}$ and $\mathrm{Pv}$, respectively. L-Bi and L-Pv, field L soil in pots were grown for Bi and Pv, respectively. 

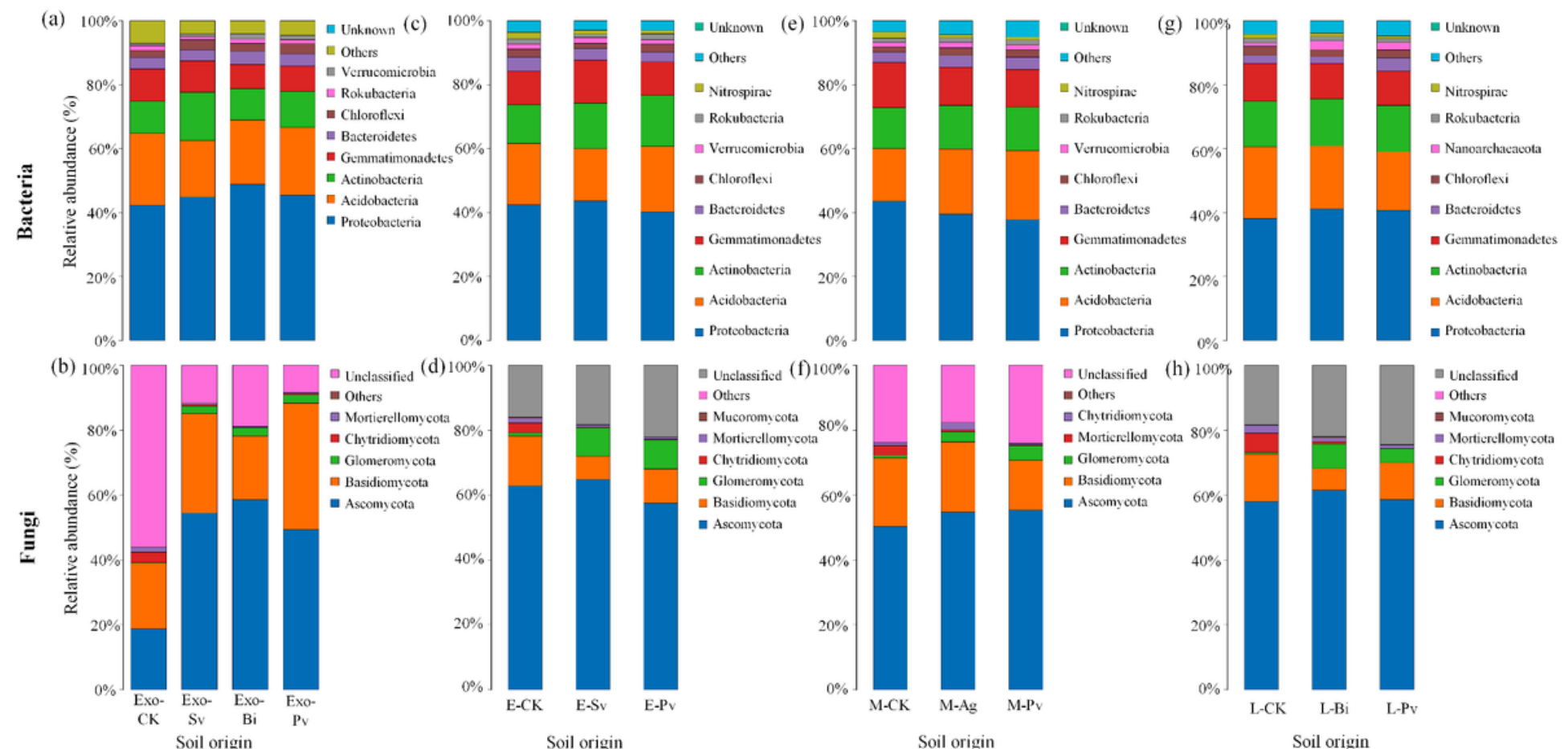

E Unclassified (h) $100 \%$ Others

E Chutridiomveota

- Morticrellomycota $80 \%$

- Glomeromy cota

E Basidiomycota

- Ascomycota

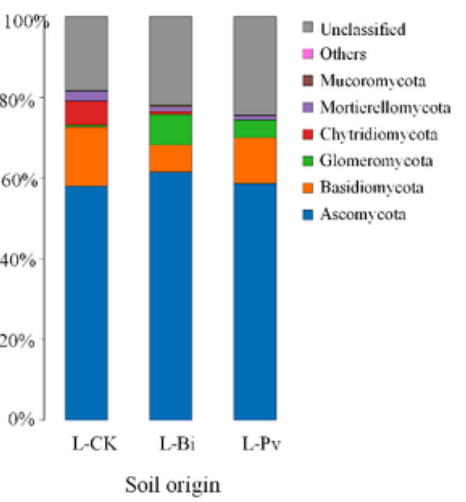

Figure 3

Relative abundance of soil bacteria $(a, c, e, g)$ and fungi $(b, d, f, h)$ at the phylum level $(n=4)$. Notes: Exo-CK, field exotic species (Exo) soil in pots was not planted. Exo-CK, E-CK, M-CK, and L-CK, no plants were prepared. Exo-Sv, Exo-Bi, and Exo-Pv, field Exo soil in pots were grown for Setaria viridis (Sv), Bothriochloa ischaemum (Bi), and Panicum virgatum (Pv), respectively. E-Sv and E-Pv, field E soil in pots were grown for Sv and Pv, respectively. M-Ag and M-Pv, field $\mathrm{M}$ soil in pots was grown for $\mathrm{Ag}$ and $\mathrm{PV}$, respectively. $\mathrm{L}-\mathrm{Bi}$ and $\mathrm{L}-\mathrm{PV}$, field $\mathrm{L}$ soil in pots were grown for $\mathrm{Bi}$ and $\mathrm{Pv}$, respectively.
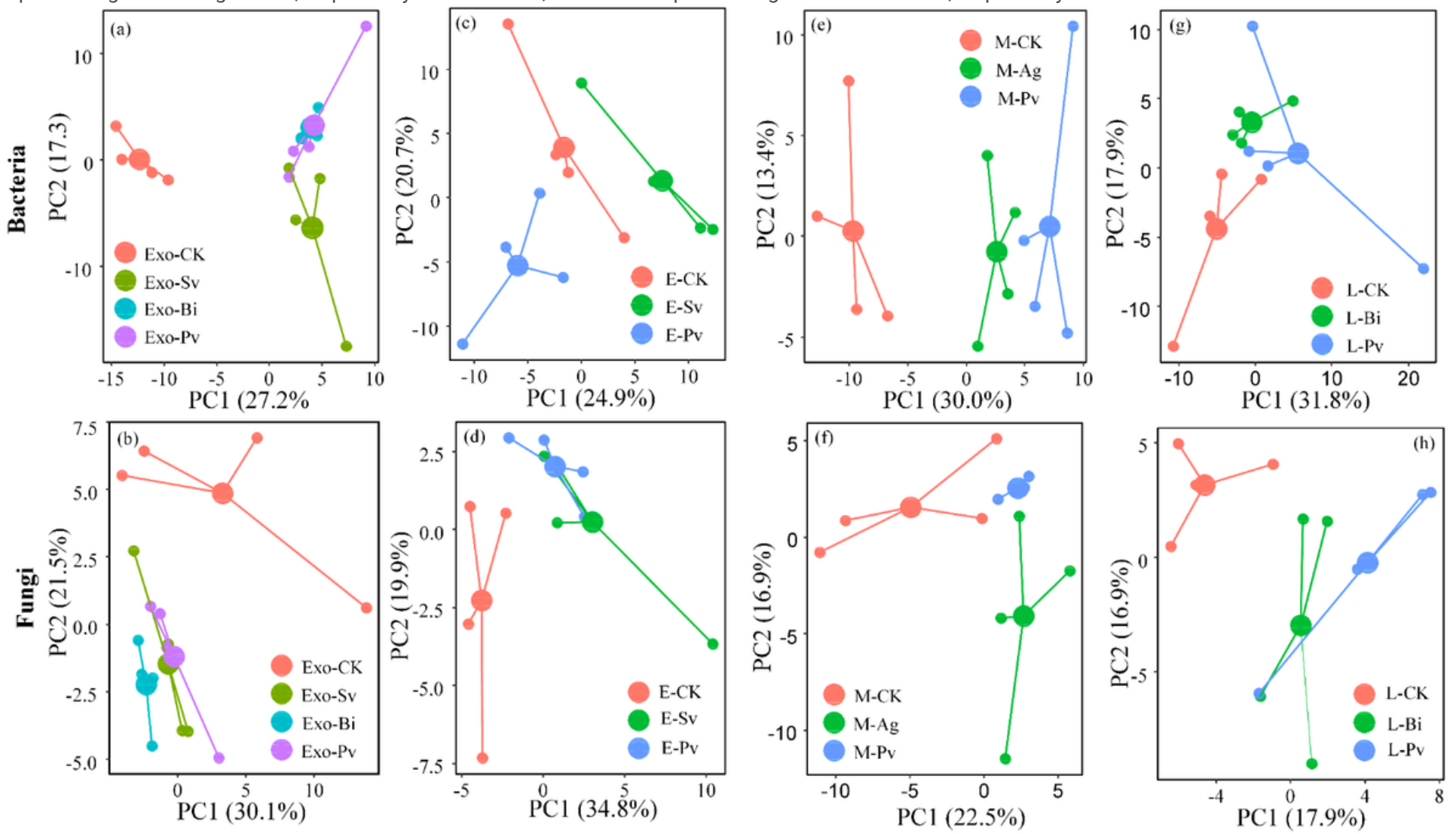

Figure 4 
Principal component analysis (PCA) ordinations of soil bacterial $(\mathrm{a}, \mathrm{c}, \mathrm{e}, \mathrm{g})$ and fungal $(\mathrm{b}, \mathrm{d}, \mathrm{f}, \mathrm{h})$ communities that were compared using the Bray-Curtis distance. Notes: Exo-CK, E-CK, M-CK, and L-CK, no plants were prepared. Exo-Sv, Exo-Bi, and Exo-Pv, field Exo soil in pots were grown for Setaria viridis (Sv), Bothriochloa ischaemum (Bi), and Panicum virgatum (Pv), respectively. E-Sv and E-Pv, field E soil in pots were grown for Sv and Pv, respectively. M-Ag and M-Pv, field $\mathrm{M}$ soil in pots was grown for $\mathrm{Ag}$ and $\mathrm{Pv}$, respectively. $\mathrm{L}-\mathrm{Bi}$ and $\mathrm{L}-\mathrm{Pv}$, field $\mathrm{L}$ soil in pots were grown for $\mathrm{Bi}$ and $\mathrm{Pv}$, respectively.
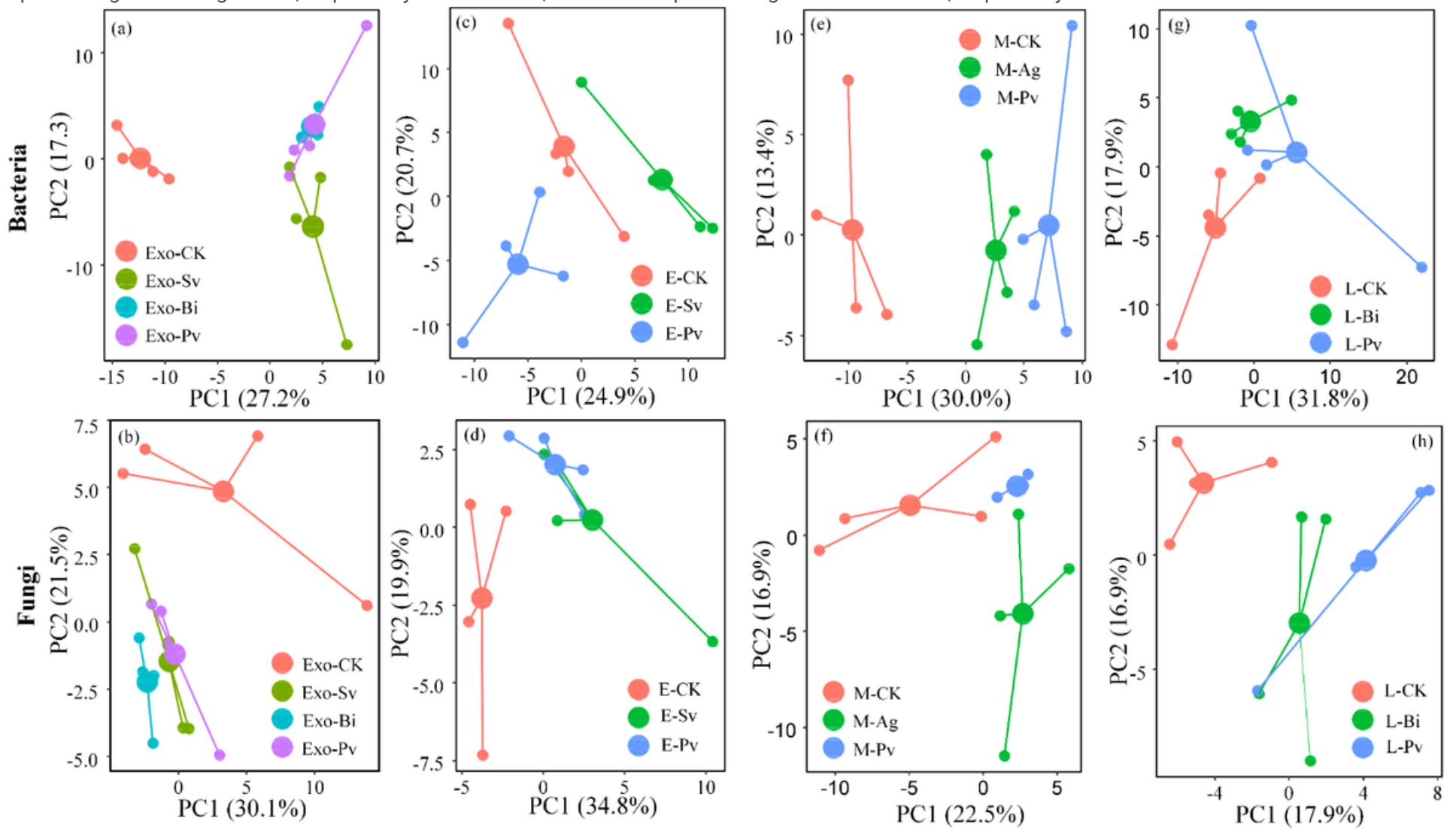

Figure 4

Principal component analysis (PCA) ordinations of soil bacterial $(a, c, e, g)$ and fungal $(b, d, f, h)$ communities that were compared using the Bray-Curtis distance. Notes: Exo-CK, E-CK, M-CK, and L-CK, no plants were prepared. Exo-Sv, Exo-Bi, and Exo-Pv, field Exo soil in pots were grown for Setaria viridis (Sv), Bothriochloa ischaemum (Bi), and Panicum virgatum (Pv), respectively. E-Sv and E-Pv, field E soil in pots were grown for Sv and Pv, respectively. M-Ag and M-Pv, field M soil in pots was grown for $\mathrm{Ag}$ and $\mathrm{Pv}$, respectively. L-Bi and L-Pv, field $\mathrm{L}$ soil in pots were grown for $\mathrm{Bi}$ and $\mathrm{Pv}$, respectively. 

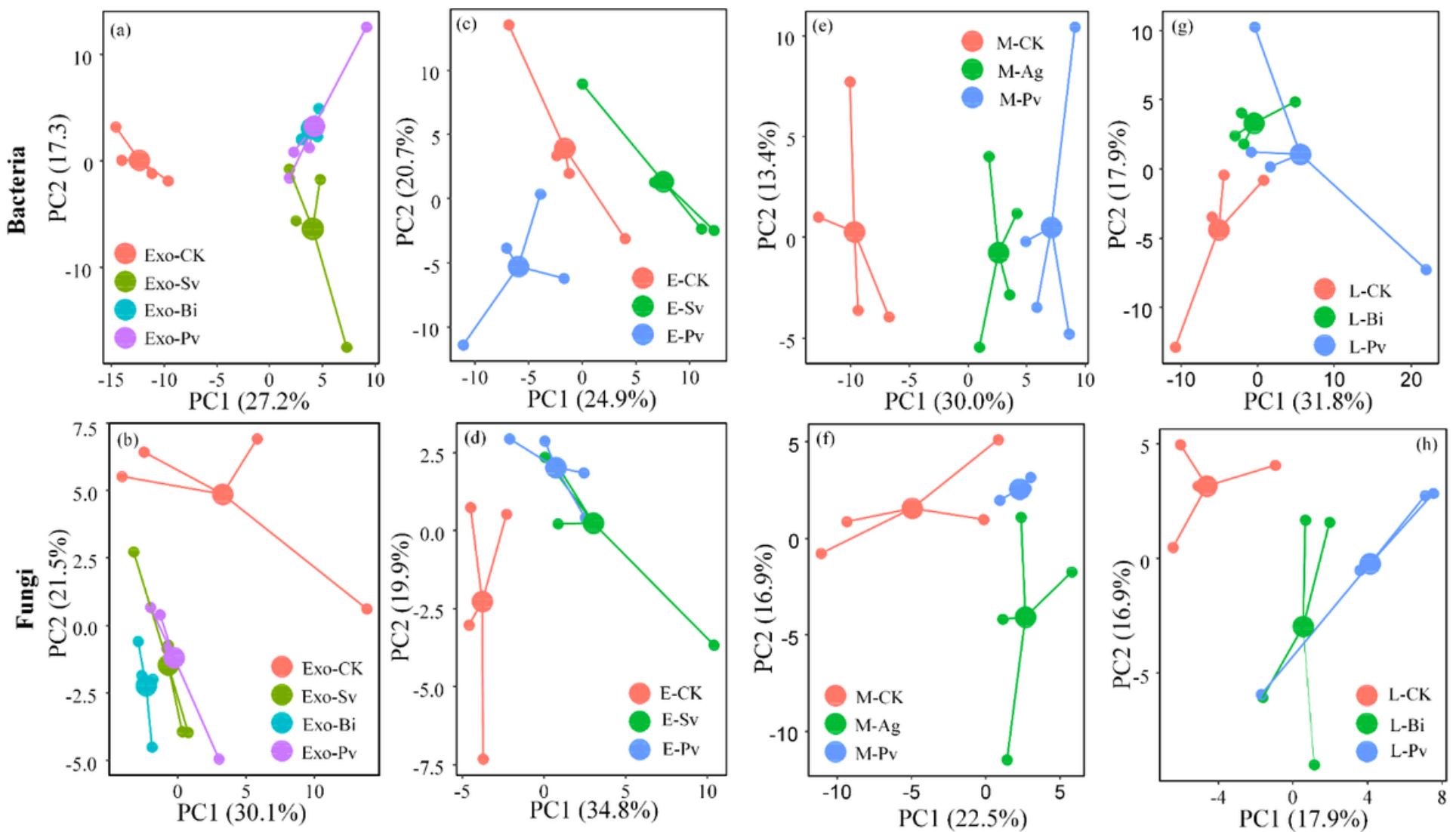

\section{Figure 4}

Principal component analysis (PCA) ordinations of soil bacterial $(\mathrm{a}, \mathrm{c}, \mathrm{e}, \mathrm{g})$ and fungal $(\mathrm{b}, \mathrm{d}, \mathrm{f}, \mathrm{h})$ communities that were compared using the Bray-Curtis distance. Notes: Exo-CK, E-CK, M-CK, and L-CK, no plants were prepared. Exo-Sv, Exo-Bi, and Exo-Pv, field Exo soil in pots were grown for Setaria viridis (Sv), Bothriochloa ischaemum (Bi), and Panicum virgatum (Pv), respectively. E-Sv and E-Pv, field E soil in pots were grown for Sv and Pv, respectively. M-Ag and M-Pv, field M soil in pots was grown for $\mathrm{Ag}$ and $\mathrm{Pv}$, respectively. $\mathrm{L}-\mathrm{Bi}$ and $\mathrm{L}-\mathrm{Pv}$, field $\mathrm{L}$ soil in pots were grown for $\mathrm{Bi}$ and $\mathrm{Pv}$, respectively. 


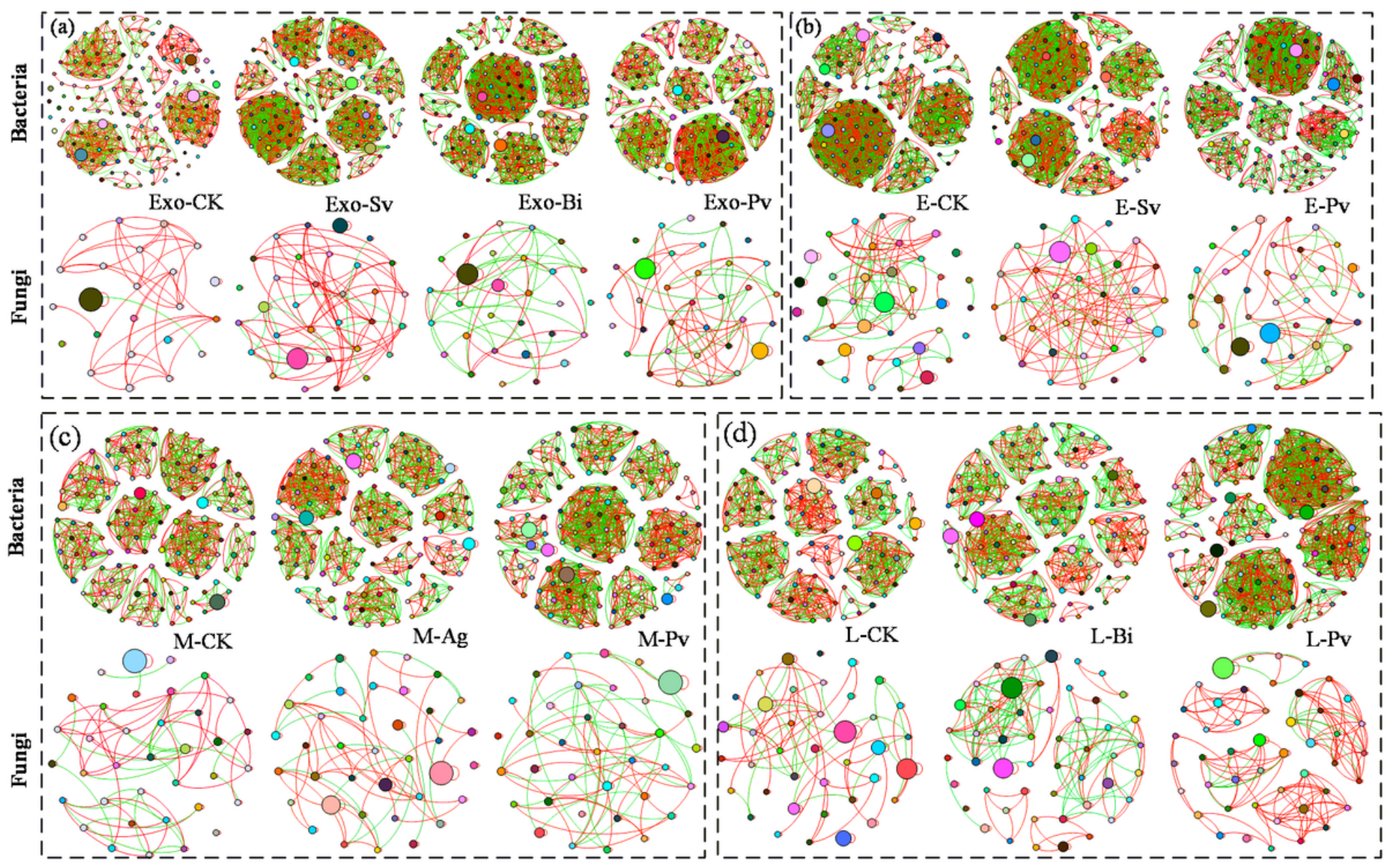

Figure 5

Correlation networks of soil bacteria and fungi at the genus level. Notes: One node represents one genus type. The size of the node represents the relative abundance of a genus. Nodes have different colors that relate to the genus. Red lines represent positive correlations, green lines represent negative correlations. Exo-CK, E-CK, M-CK, and L-CK, no plants were prepared. Exo-Sv, Exo-Bi, and Exo-Pv, field Exo soil in pots were grown for Setaria viridis (Sv), Bothriochloa ischaemum (Bi), and Panicum virgatum (Pv), respectively. E-Sv and E-Pv, field E soil in pots were grown for Sv and Pv, respectively. M-Ag and M$\mathrm{Pv}$, field $\mathrm{M}$ soil in pots was grown for $\mathrm{Ag}$ and $\mathrm{PV}$, respectively. $\mathrm{L}-\mathrm{Bi}$ and $\mathrm{L}-\mathrm{PV}$, field $\mathrm{L}$ soil in pots were grown for $\mathrm{Bi}$ and $\mathrm{Pv}$, respectively. 


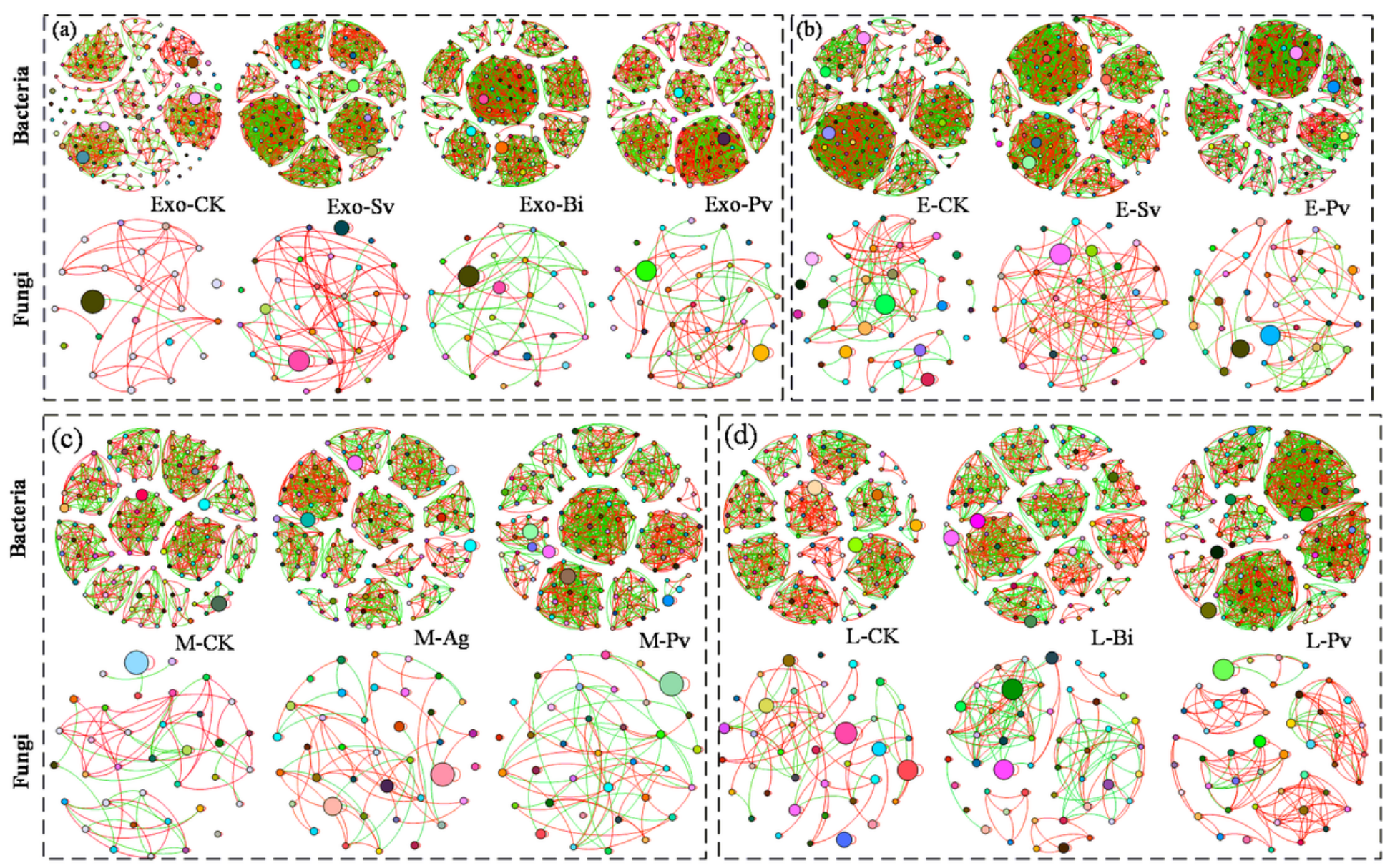

Figure 5

Correlation networks of soil bacteria and fungi at the genus level. Notes: One node represents one genus type. The size of the node represents the relative abundance of a genus. Nodes have different colors that relate to the genus. Red lines represent positive correlations, green lines represent negative correlations. Exo-CK, E-CK, M-CK, and L-CK, no plants were prepared. Exo-Sv, Exo-Bi, and Exo-Pv, field Exo soil in pots were grown for Setaria viridis (Sv), Bothriochloa ischaemum (Bi), and Panicum virgatum (Pv), respectively. E-Sv and E-Pv, field E soil in pots were grown for Sv and Pv, respectively. M-Ag and M$\mathrm{Pv}$, field $\mathrm{M}$ soil in pots was grown for $\mathrm{Ag}$ and $\mathrm{PV}$, respectively. $\mathrm{L}-\mathrm{Bi}$ and $\mathrm{L}-\mathrm{PV}$, field $\mathrm{L}$ soil in pots were grown for $\mathrm{Bi}$ and $\mathrm{Pv}$, respectively. 


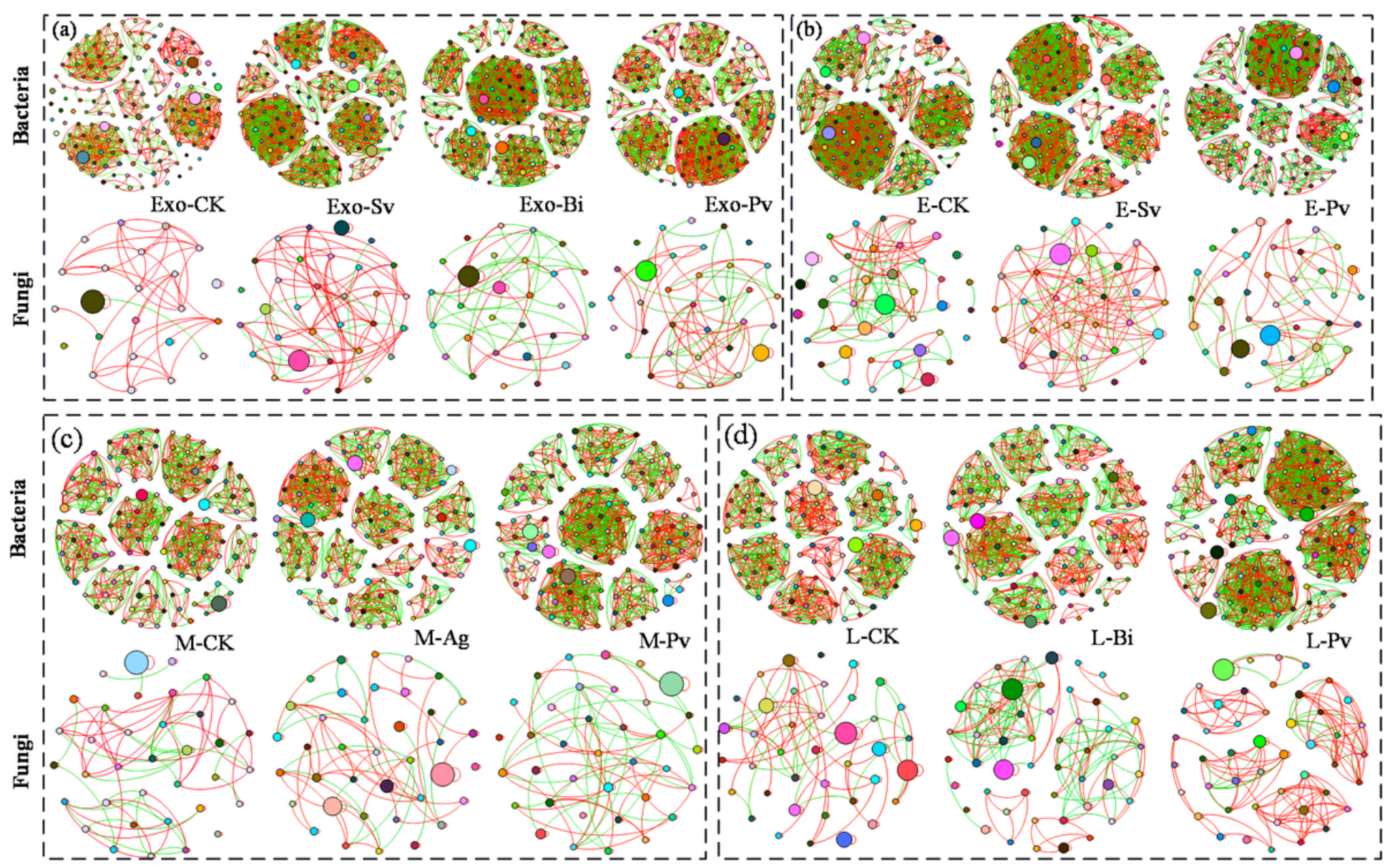

Figure 5

Correlation networks of soil bacteria and fungi at the genus level. Notes: One node represents one genus type. The size of the node represents the relative abundance of a genus. Nodes have different colors that relate to the genus. Red lines represent positive correlations, green lines represent negative correlations. Exo-CK, E-CK, M-CK, and L-CK, no plants were prepared. Exo-Sv, Exo-Bi, and Exo-Pv, field Exo soil in pots were grown for Setaria viridis (Sv), Bothriochloa ischaemum (Bi), and Panicum virgatum (Pv), respectively. E-Sv and E-Pv, field E soil in pots were grown for Sv and Pv, respectively. M-Ag and M$\mathrm{Pv}$, field $\mathrm{M}$ soil in pots was grown for $\mathrm{Ag}$ and $\mathrm{PV}$, respectively. $\mathrm{L}-\mathrm{Bi}$ and $\mathrm{L}-\mathrm{PV}$, field $\mathrm{L}$ soil in pots were grown for $\mathrm{Bi}$ and $\mathrm{Pv}$, respectively. 


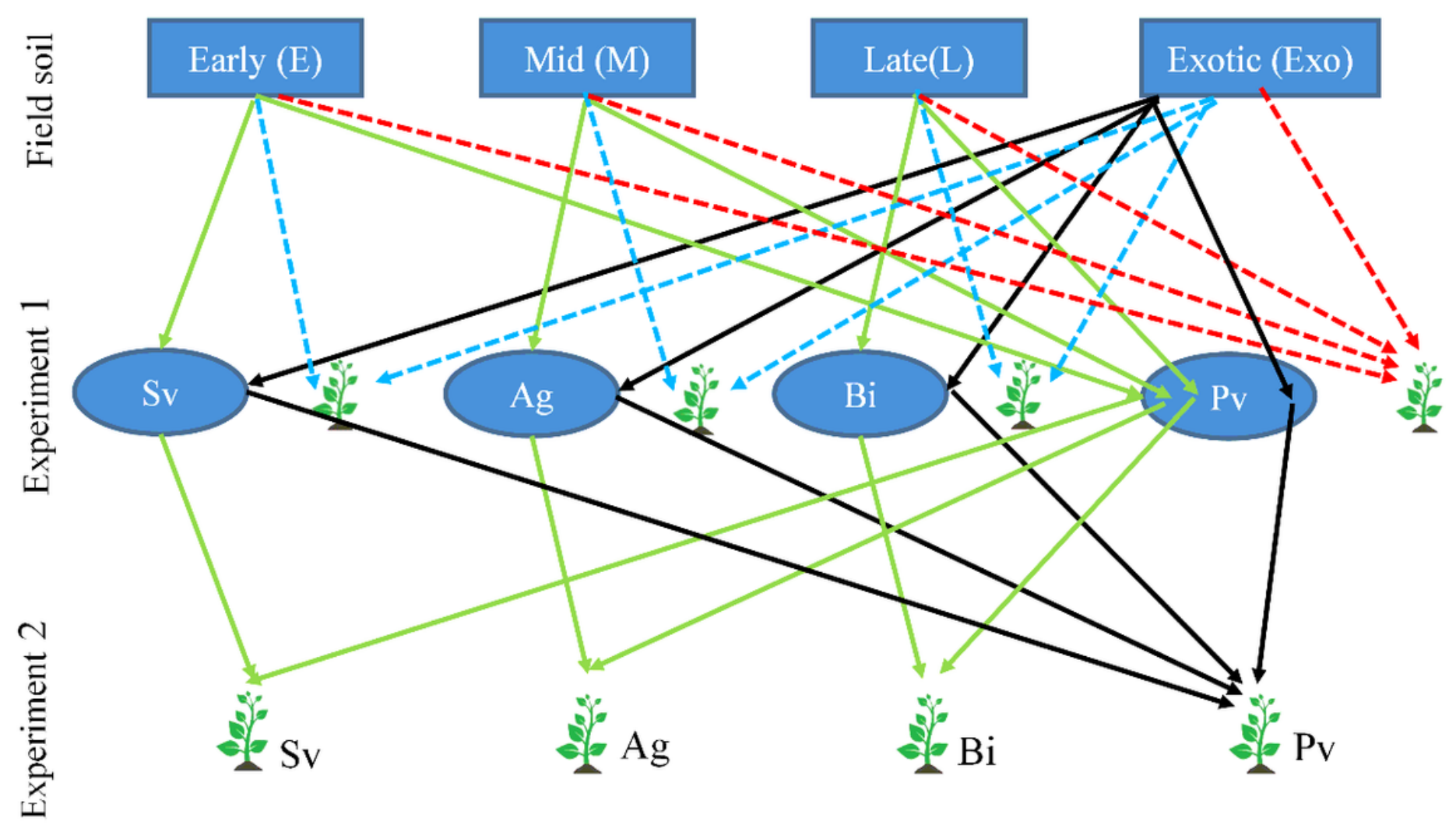

Figure 6

Experimental design and planting scheme. Experiment 1: field soil from early replacement succession (E) was placed in pots and Setaria viridis (Sv) was grown; field soil of middle replacement succession (M) was placed in pots and Artemisia gmelinii (Ag) was grown; and field soil of later replacement succession (L) was placed in pots and Bothriochloa ischaemum (Bi) was grown (see blue dotted line); field soil of exotic species (Exo) was grown in pots for $\mathrm{Sv}, \mathrm{Ag}, \mathrm{Bi}$, and Panicum virgatum (Pv) (see red dotted line), with 10 replicates. Experiment 2: Pv was grown in soils created from native species (Sv, Ag, and Bi) versus being grown in their own soils originating from Exo field soils (see black solid line); native species Sv, Ag, and Bi were grown in their own soils versus being grown in soils created from exotic species originating from the field soils of these native species (see green solid line). All plants were grown for four months. 


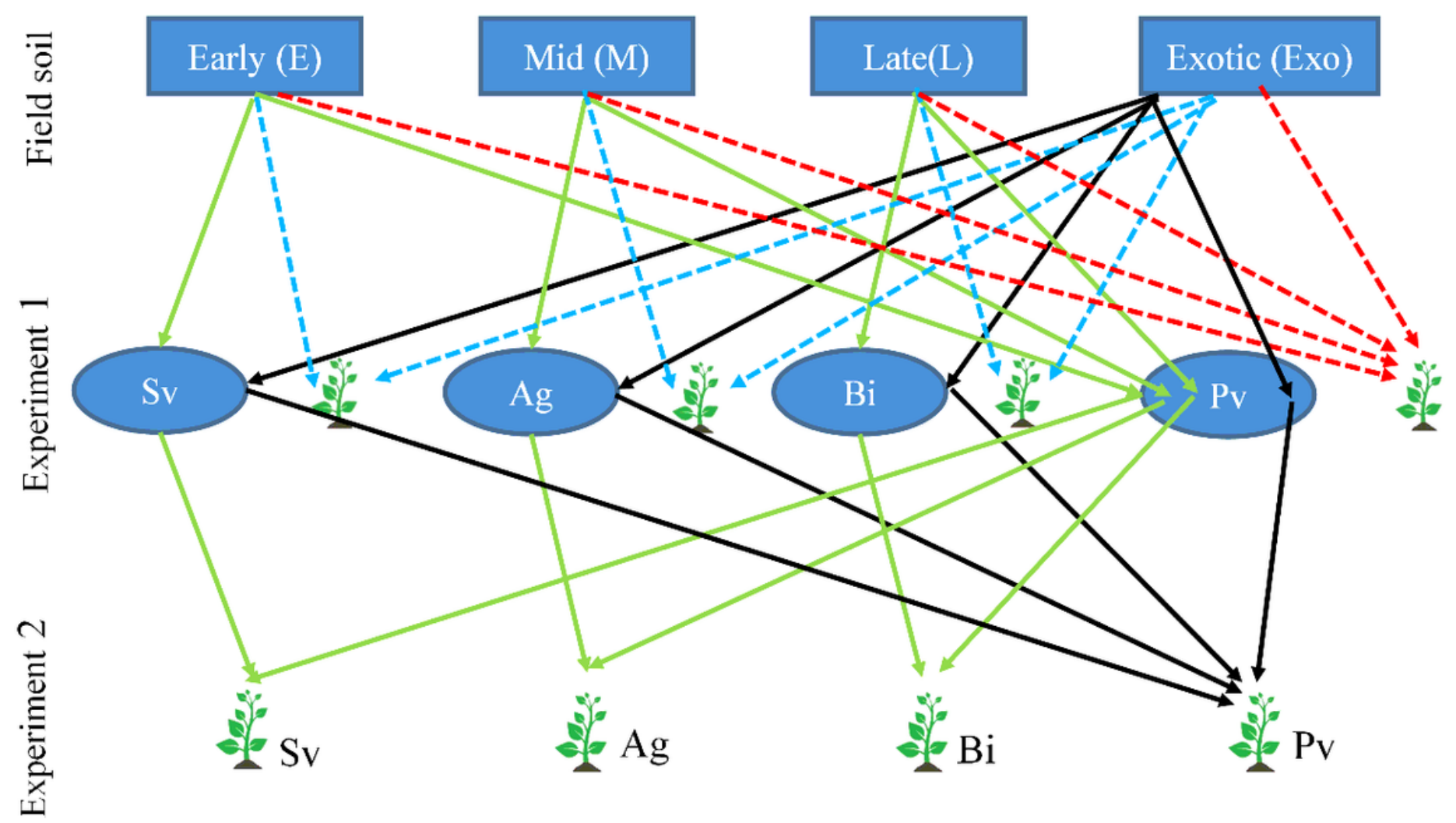

Figure 6

Experimental design and planting scheme. Experiment 1: field soil from early replacement succession (E) was placed in pots and Setaria viridis (Sv) was grown; field soil of middle replacement succession (M) was placed in pots and Artemisia gmelinii (Ag) was grown; and field soil of later replacement succession $(\mathrm{L})$ was placed in pots and Bothriochloa ischaemum (Bi) was grown (see blue dotted line); field soil of exotic species (Exo) was grown in pots for $\mathrm{Sv}, \mathrm{Ag}, \mathrm{Bi}$, and Panicum virgatum (Pv) (see red dotted line), with 10 replicates. Experiment 2: Pv was grown in soils created from native species (Sv, Ag, and Bi) versus being grown in their own soils originating from Exo field soils (see black solid line); native species Sv, Ag, and Bi were grown in their own soils versus being grown in soils created from exotic species originating from the field soils of these native species (see green solid line). All plants were grown for four months. 


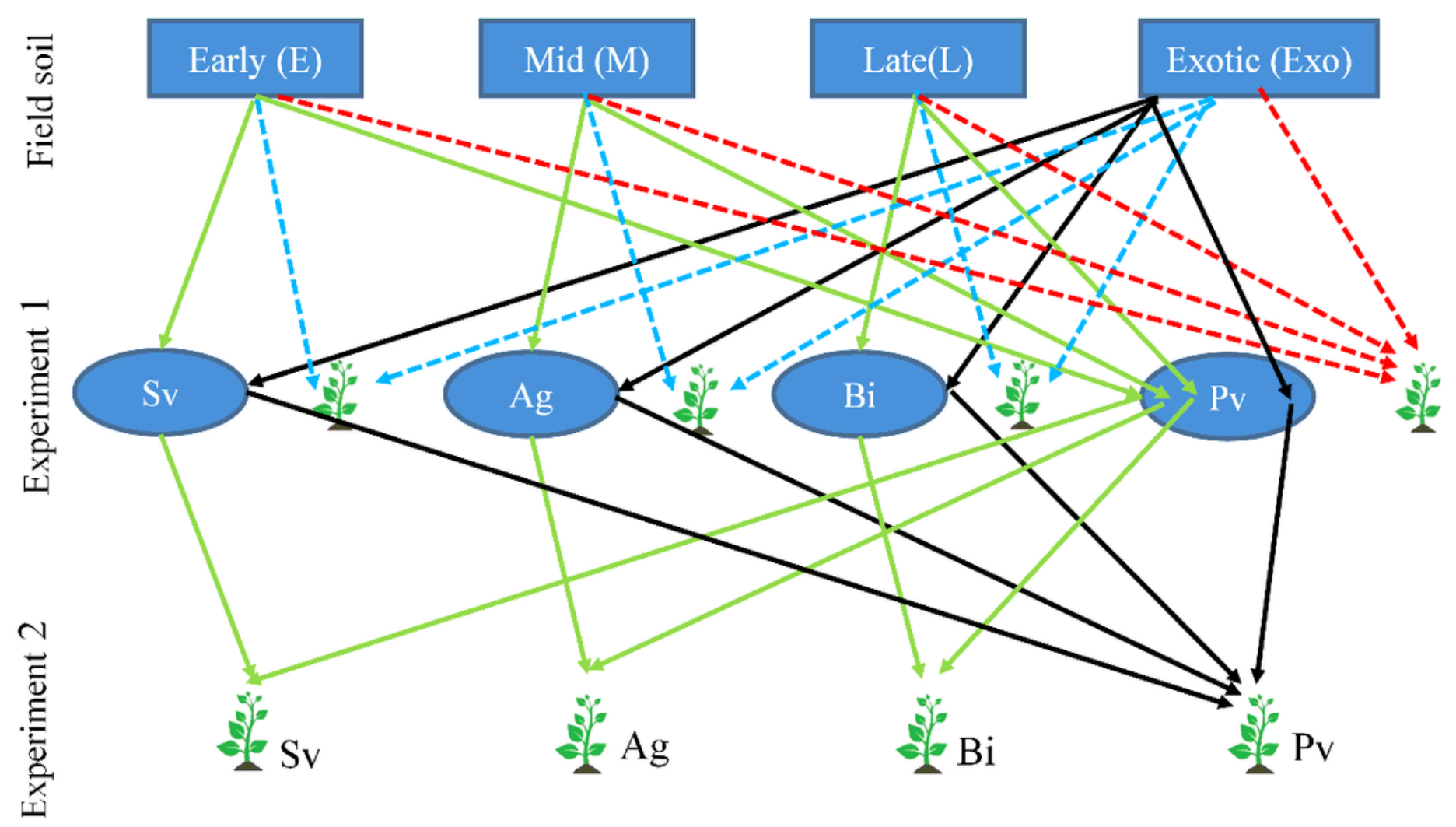

Figure 6

Experimental design and planting scheme. Experiment 1: field soil from early replacement succession (E) was placed in pots and Setaria viridis (Sv) was grown; field soil of middle replacement succession (M) was placed in pots and Artemisia gmelinii (Ag) was grown; and field soil of later replacement succession (L) was placed in pots and Bothriochloa ischaemum (Bi) was grown (see blue dotted line); field soil of exotic species (Exo) was grown in pots for $\mathrm{Sv}, \mathrm{Ag}, \mathrm{Bi}$, and Panicum virgatum (Pv) (see red dotted line), with 10 replicates. Experiment 2: Pv was grown in soils created from native species (Sv, Ag, and Bi) versus being grown in their own soils originating from Exo field soils (see black solid line); native species Sv, Ag, and Bi were grown in their own soils versus being grown in soils created from exotic species originating from the field soils of these native species (see green solid line). All plants were grown for four months.

\section{Supplementary Files}

This is a list of supplementary files associated with this preprint. Click to download.

- Appendix.docx

- Appendix.docx 